[rh] A Consideration of New Perspectives and Places

\title{
The Micro-Dynamics of Intra-Organizational and Individual Behavior and Their Role in Organizational Ambidexterity Boundaries
}

\author{
Peter Stokes, Neil Moore, Danny Moss, Martin Mathews, Simon Smith, and Yipeng Liu
}

\begin{abstract}
Organizational ambidexterity has emerged as a valuable contemporary lens on organizational design and action, examining the dynamic relationships between exploitative (extant) and explorative (evolving) resources within organizational contexts and environments. This paper analyzes the literature pertaining to ambidexterity and underlines a number of recurrent preoccupations including: definition of the nature, characteristics and normative boundaries of organizational ambidexterity; a predilection towards considering inter-firm/unit comparisons of large-scale corporate organizations; and, a concentration on the significance of the managerialistic role of senior management team's disposition and action-orientations. While a few calls have been made for a focus on the micro, predominant attention has remained on the macroaspects of organizational ambidexterity.

The aim of the paper, therefore, is to conduct a complementary study that considers the boundaries and transitions between exploitative and explorative modes at the intra-organizational, individual micro-behavioral level. To facilitate this, the paper surfaces and underscores the paradigmatic modernistic characterization of large areas of the current organizational ambidexterity literature and the implications of this. Moreover, it explores alternative potentially useful critical paradigms which assist in providing tools with which to examine the 'micro'. The research conducts an ethnographic-style study of quasi-public training and development organization in order to illustrate the above background contexts and the micro-interface and boundary of explorative and exploitative modes of organizational ambidexterity in the intraorganizational situation. Within this, the study points up the significance of the role of sensemaking in operational micro-moment individual and small-group situations, and their vital influence in ultimately underpinning, and contributing to, macro-organizational ambidextrous contexts.
\end{abstract}

Keywords: organizational ambidexterity, intra-firm/unit, micro-moments, paradigms.

Correspondence to: Peter Stokes, University of Chester Business School,University of Chester, Parkgate Lane, Chester, CH1 4BJ UK, Phone: +44 1244 511975, Fax: +44 1244 511329, Email: p.stokes@chester.ac.uk.

\section{Introduction}

The notion of organizational ambidexterity has emerged relatively recently within contemporary organizational and managerial literatures but has gained significant traction within 
organization and managerial debates and scholarship (O’Reilly \& Tushman, 2004, 2008; Raisch \& Tushmann, 2011; Birkinshaw et al. 2009; O’Reilly \& Tushman 2013). It offers an interesting new lens through which to observe and analyze issues around organization design, strategic and operational decision-making and the patterns and dynamics of organization behavior. Here, one interesting dimension of this new perspective on organization activity is in terms of the tension between choice and decisions around the disposition of 'exploitative' and 'explorative' resources. Organizational ambidexterity can be understood as the relationship and dynamic potential operating between exploitative and explorative resources and dispositions in organizational contexts. Exploitative resources generally encompass the use of more mechanistic-style processes in order to cultivate and develop extant knowledge and options. Alternatively, explorative resources are primarily concerned with facilitating the organic evolution of new knowledge, fields and opportunities accompanied by the requisite mind-sets (Kyriakopoulos \& Moorman, 2004; Jansen, George, Van den Bosch, \& Volberda, 2008; Raisch \& Birkinshaw, 2008; Birkinshaw et al., 2009; Kang \& Snell, 2009; Simsek, 2009; O’Reilly \& Tushmann, 2011; O’Reilly \& Tushmann, 2008).

The vibrant and fast-growing research stream on organizational ambidexterity is manifesting its distinctive contribution to the field of organization studies (Birkinshaw \& Gupta 2013). The flourishing of the ambidexterity literature was partially attributed to a lack of construct clarity and divergent operationalization of ambidexterity. Categorically speaking, three types of ambidexterity have been investigated in the extant literature, namely sequential, structural, and contextual ambidexterity (O’Reilly \& Tushman, 2013). Originally formulated as the punctuated equilibrium model, exploration and exploitation can be achieved following a sequential process (Gupta, Smith, \& Shalley, 2006). The notion of sequential ambidexterity asserts that organizations 
can achieve ambidexterity in a sequential manner by shifting structures over time. However, "how sequential ambidexterity occurs and the transition looks like” (O’Reilly \& Tushman, 2013: 327) remains a theoretical puzzle. To be explicit, "what does it mean to go from exploitation to exploration?” Our study fills this important gap in organizational ambidexterity by investigating the boundary of and the interplay between exploration and exploitation. A critical perspective, we argue, can significantly advance our understanding of the boundary of exploration and exploitation (Gotsi, Andriopoulos, Lewis, \& Ingram, 2010).

The organizational ambidexterity literature has produced many insights in relation to a range of varying topic domains and, in addition, a growing collection of useful case studies have been assembled (see by way of illustration O’Reilly, Harreld, \& Tushman, 2009; Sarkees, Hull \& Prescott, 2010; Prieto \& Perez Santana, 2012). Significantly, while not exclusively, a majority of existing work on organizational ambidexterity tends to focus its scrutiny on ambidexterity in relation to entities or units of analysis such as company or organization - in other words, overall or holistic entity. Furthermore, in relation to this macro-perspective on organization, many accounts tend to examine these issues from the point of view of the senior management or executive team rather than from an individual employee or sub-team perspective. However, the insights from individual employee or sub-team perspective are of significant importance to theoretically advancing our understanding of organizational ambidexterity. Although the breadth of the work conducted hitherto represents important progress, a number of scholars have equally expressed concern that whilst it has been the 'macro' dimensions of organizational ambidexterity which have predominantly attracted scholarly attention, micro-perspectives, remain relatively under-explored (see inter alia Mom, Van den Bosch, \& Volberda, 2009; Raisch \& Birkinshaw, 2008; Birkinshaw \& Gupta, 2013). A recent literature review found out there has been little 
research of ambidexterity at the individual level (Turner, Swart, \& Maylor, 2013). Thus, the aim and objectives of this paper concern making a valuable contribution to the growing body or scholarly study around the notion of organizational ambidexterity by uncovering valuable insights into the manifestation of ambidextrous behaviors at the individual actor level within intraorganizational settings. The starting point in this study is the premise that organizational ambidexterity presents itself as a variable dependent on, and determined by, the composite microeffects of socially constructed independent individual and group behaviors. This in turn leads to the macro-conditions of organizational ambidexterity. This paper aims to examine micro-aspects in organizational ambidexterity and, here, designates 'micro' as concerning that which is individual, spatially local, and involved with the micro-moment of experience and behavior.

\section{INSERT DIAGRAM 1 HERE}

This produces the following research question for the present paper and argument:

What are the types, forms and conditions of localized, individual, behavioral and structural actions and processes that shape organizational ambidexterity at the boundaries of exploitative and explorative modes in intra-organizational contexts?

This question will involve two related actions. To consider an intra-organizational context (in contrast to the inter-firm case work widely conducted hitherto) which, following on from kindred studies (see Kase, Paauwe, \& Zupan, 2009) will continue to build in-depth analyses. 
Secondly, to introduce critical perspectives and micro-moments which have the potential to generate insights into the everyday actions, reactions and exchanges which, in turn, may contribute to the understanding and construction of complex macro-organizational ambidextrous environments.

In pursuit of the above research question the paper adopts the following structure. First, an overview of the field of organizational ambidexterity is presented. Significant gaps within the literature are highlighted and this is supported by a discussion of modernism and critical perspectives leading to a justification for the approach adopted. This invokes and explains the notion of the micro-moment as a site of sense-making for individuals. Following this, the ethnographic research methodology is presented. The subsequent findings and discussion then explore organizational ambidexterity at the individual level in an intra-organizational context employing the data collected. Within this section, a table is presented to assist in understanding the character, and often paradoxical relationship, between exploitative and explorative boundaries and modes. Finally, the paper highlights the limitations and future research directions, implications and overarching conclusions respectively. Overall, the paper seeks to provide a valuable contribution to the field by surfacing and exploring important micro-level aspects which will complement the studies already conducted and enhance theoretical understanding and managerial practice in the ambidexterity domain.

\section{Literature Review}

\section{The Conceptual and Contextual Emergence of Organizational Ambidexterity.}

The body of literature on organizational and management process design, in relation to which organizational ambidexterity is situated, is longstanding and extensive (Pettigrew, 1973; 
Duncan, 1976; Mintzberg, 1994, 2010; Watson, 1994; Clegg, Kornberger, \& Pitsis, 2011). Historically, early discussions and phases of organizational design have been predicated primarily on functionalist, mechanistic and structuralist assumptions. Subsequent developments in both practice and literature have explored and fused the functionalist with more resourced-based, organic, flexible, dynamic and contingency-kindred approaches (Gibson \& Birkenshaw, 2004; Menguc \& Auh, 2008; Greenwood \& Miller, 2010). As such, organizational design has experienced waves of analysis over more recent decades (see by way of illustration Clark, 1972; Pfeffer, 1978; Mansfield, 1986; Rao \& Rao, 1999; Stanford, 2012). Typically, discussions on organizational design have tended to draw on a range of wider and related fields such as, for example, strategic management (De Wit \& Meyer, 2012; Winter and Szulanski, 2001; Helfat et al., 2007), organization theory (Triplett, 2007; Holmqvist, 2004), organizational behavior (Jones, 2012; Johns, 2006), work psychology (Hatch \& Cunliffe, 2007; Burton, Obel, \& De Sanctis, 2011) and that HRM practices can facilitate SMEs’ entrepreneurial performance (Hayton, 2003).

To some degree, the varying theoretical lenses above can be seen to offer two separate but broadly related perspectives on organizational design and change: strategic management and organization theory - both providing a broader macro-perspective - whereas the organizational behavior and work psychology schools frequently offer a more micro-perspective. Equally, the field of change management can also be seen to offer further sets of lenses through which to observe such developments. Change management draws together the macro-strategic intent of organizational planning and action together with the myriad micro-details and issues that require resolution between individuals and stakeholder groups within firms. It is against the ever-evolving and rich backdrop of the above fields that a fresh array of approaches towards organizational analysis has emerged. The more contemporary and novel perspectives tend to highlight a role for 
notions such as flexibility, isomorphism, agility, ambiguity, critical approaches and even 'messiness’ (Jackson \& Carter, 2007; Jin, Hopkins, \& Wittmer, 2010; Ackermann \& Eden, 2011; Stokes, 2011; Shaw 2012). It is in relation to a confluence of these historical and contemporary contexts that the concept of organizational ambidexterity has emerged and is making its contribution.

\section{The Concept of Organizational Ambidexterity.}

The relatively nascent and emergent concept of organizational ambidexterity has received increasing attention as an approach to organizational design. Organizational ambidexterity, can be understood as the nature, operation and interface of exploitative dimensions of organizations (i.e. evolving and building on extant resources and structures) and explorative dimensions of organizational dynamics (i.e. shaping and innovating fresh domains and future opportunities) (Duncan, 1976; He \& Wong, 2004; Raisch \& Birkinshaw, 2008; Jansen et al., 2008; Simsek, 2009; Raisch, Birkinshaw, Probst, \& Tushamn, 2009; O’Reilly et al., 2009; Groysberg \& Lee, 2009; Andriopoulos \& Lewis, 2009; O’Reilly \& Tushmann , 2011; Prieto \& Pérez Santana, 2012; Hill \& Birkinshaw, 2012). In the main, exploitative dimensions tend to be extant, 'proximate' and more 'predictable' and explorative aspects tend to be more developmental, remote and 'unpredictable' in nature (Hill \& Birkinshaw, 2012) following March (1991:85), Baum et al., (2000: 768) and Lin, Yang, \& Demirkan, (2007: 1645).

As indicated above, the expression of organizational ambidexterity is commonly portrayed in terms of exploitative and exploratory capacities (Levinthal \& March, 1993; He \& Wong, 2004; Birkinshaw \& Gibson, 2004; Lubatkin, Simsek, Ling, \& Veiga, 2006; Jansen et al., 2008; Konstantinos et al., 2011). Moreover, these concepts are often linked to managerial ideas of 
learning capacity and usage of resources (Im \& Rai, 2008; Kostopoulos \& Bozionelos, 2011). In the case of exploitative aspects, this term applies where an organization is cultivating and fully engaging the talents and capacities it already possesses. On the other hand, in relation to exploratory processes, the attention is directed to what may be possible to create and generate in addition to existing resources (March, 2003; Benner \& Tushman, 2003; O’Reilly \& Tushman, 2004; Menguc \& Auh, 2008; Lavie, Stettner, \& Tushman, 2010; Voss \& Voss, 2012). Alternatively, these processes are occasionally expressed in a more commercially-oriented sense as innovative exploration or innovative exploitation (Bierly, Damanpour, \& Santoro, 2009). For example, innovative exploration focuses upon meeting the requirements of new customer and markets. It involves 'new knowledge’ and may involve departure from existing knowledge. It is characterized by experimentation, flexibility and divergent thinking. However, innovative exploitation focuses upon existing customers or markets. It involves an incremental approach and relies upon efficiency, refinement, focus and a broadening of existing knowledge (i.e. the 'known').

Arguably, while the notion of 'organizational ambidexterity' may appear to be a relatively nascent one, judged by the management literature, many of the ideas and constructs underpinning thinking about ambidexterity in the organizational context can be shown to have a relatively rich and extensive lineage (Burgelman, 1991; Tushman \& O’Reilly, 1996; Volberda, 1996; Eisenhardt \& Martin, 2000; Benner \& Tushman, 2003; and Kouropalatis, Hughes, \& Morgan, 2012).

The above outline on organizational ambidexterity indicates a broad characterization of the domain, however, evidently there are sector, scale and context considerations which also play a role. Chang, Hughes, and Hotho, (2011), for example, provide a valuable case that explores exploitative/explorative balances applicable to small and medium-sized business contexts. One 
recent study identified that organizational diversity and shared vision are conducive for organizations to achieve ambidexterity (Wang \& Rafiq, 2014). Moreover, Shafer, Dyer, Kilty, Amos, and Ericksen, (2001) examine the straplines of a corporate revitalization plan for a healthcare company. Further themes and contexts in which some of the above issues have been scrutinized in the literature include inter alia: high-tech SMEs (Gedajlovic, Cao, \& Zhang, 2011); human resource practices in Spain (Prieto \& Pérez Santana, 2012); vacillation (Boumgarden, Nickerson, \& Zenger, 2012); acquisitions (Nemanich \& Vera, 2008); performance (Patel et al., 2012); the performance of international new ventures (Han and Celly, 2008); technology sourcing in US manufacturing companies (Rothaermel \& Alexandre, 2009); balancing exploration and exploitation in the global fuel cell industry (Russo \& Vurro, 2010); environmental dynamism and competitiveness in Chinese firms engaged in new product development (Yang \& Li, 2011); IBM (O’Reilly, Harreld, \& Tushman, 2009); human capital in manufacturing firm supply chain contexts (Jin, Hopkins, \& Wittmer 2010); team and scenario planning (Chermack, Bodwell, \& Glick, 2010); learning in project teams (Kostopoulos and Bozionelos, 2011); elite recruitment and professional service firms (2009); the mediating role of integration systems (2009); and transformational leadership (Jansen et al., 2008).

In relation to the broad context outlined above, this paper aims to make a number of contributions to the coverage of organizational ambidexterity. One of these is to focus its operation in relation to a quasi-public sector organization which has hitherto been under-explored. Moreover, in undertaking this it introduces, develops and adopts a critical perspective critique which affords the opportunity to comment on the dominant paradigms operating in organizational ambidexterity commentary. This leads to the two opening propositions: 
Proposition 1: Quasi-public contexts are an under-explored context and novel, specific and valuable data will be able to be determined.

Proposition 2: Application of a critical perspective lens on organizational ambidexterity will be effective in identifying behavioral shifts from relatively conservative modernistic exploitative states to more radical critical explorative conditions.

In order to accomplish the development and exploration of these propositions the literature is discussed through subsequent stages, encapsulated as discussions on: 'Summarizing Gaps and Characterizations in Organizational Ambidexterity'; 'Exploring the Role of Modernism in Organizational Ambidexterity and its Limitations'; 'Applying Critical Approaches to Organizational Ambidexterity'; and 'Lived Experience on the Boundary of Ambidextrous Balance'. Each of these sections signals issues in relation to which potential propositions and contributions are identified. Proposition 2 is further expanded and developed into four additional propositions. These are subsequently addressed and explored in the various sections of the discussion and findings.

\section{Summarizing Gaps and Characterizations in Organizational Ambidexterity.}

The predominant foci of commentaries on organizational ambidexterity have tended to look at the macro-perspective of the firms or inter-firm conditions. Moreover, the argument above has established that the micro-interaction and shifts between exploitative and explorative dimensions of organizational ambidexterity can represent a serious difficulty for some organizational members. A closer examination of micro-moments and micro-situations involving employees organizational experiences at all levels can assist in better understanding behavior across exploitative and explorative boundaries. Through this enhanced understanding it is possible to evidence and understand the ways in which certain mind-sets engender particular coping mechanisms and strategies. Furthermore, a call to consider the implications of the 'micro' context aligns with a number of emergent concerns in the field. Mom et al., (2009: 812) have stressed that: 
'Previous research focuses on firm and business unit level ambidexterity. Therefore, conceptual and empirically validated understanding about ambidexterity at the individual level of analysis is very scarce'.

Moreover, Raisch \& Birkinshaw (2008: 401) have, in a similar vein, signaled the need for a more 'granular view of boundaries' in organizational ambidextrous contexts by which they allude to a need for more data at the interface of exploitative and exploratory dynamics (Gupta et al., 2006). Consolidating the argument developed thus far, the current discussion has identified that the extant organizational ambidexterity literature clusters around a particular set of foci encompassing:

- $\quad$ analyses and explorations of the nature of organizational ambidexterity

[This definitional phase is important and to be expected in the early stages of the debate for an evolving theoretical domain];

- a focus on large-scale and/or corporate organizations rather than smaller scale entities and non-corporate enterprises and settings

[This concerns a preoccupation with the overall entity; firm or enterprise (and especially corporate organizations) particularly in relation to concerns over generating flexibility, agility and consequent competitive advantage];

- within the above predilection on corporate contexts there is a focus on senior management teams and a privileging of the managerial role rather than directing attention towards the individual interaction and operational micro-level work of an organization (be that individual manager or employee)

[Even where valuable studies have been conducted on, for example, small to medium-sized enterprises the focus has privileged examination of the role of senior management teams 
or CEOs (see Lubatkin et al. 2012; Nadkarni \& Herrmann, 2010; Sarkees et al., 2010; Chang \& Hughes, 2012; Mihalache, Jansen, Van den Bosch, \& Volberda, 2014)].

In order to investigate the reasons and causes for the above characterization of the literature and the potential for micro-aspects of sense-making and behavior at the boundaries of exploitative and explorative aspects of organizational ambidexterity it will be useful to explore briefly the paradigms underlying the phenomenon. This leads to a development in the critical aspects of the argument and hence proposition 2a:

Proposition 2a: The micro-aspects of organizational ambidexterity will reveal the 'granular' dimensions of the phenomenon at the boundary of exploitative and explorative interaction and transitions by individuals between the two states and indicate how the micro creates the macro.

\section{Exploring the Role of Modernism in Organizational Ambidexterity and its Limitations.}

The tendency for large strands of organizational ambidexterity writing to focus on the above-mentioned 'macro' dimensions can be explained through its underlying modernistic frames of reference. A knowledge of this will facilitate the development of a more 'granular view' (Raisch \& Birkinshaw, 2008:401) and insights to the often complex boundaries of the interaction of exploitative and explorative modes of organizational ambidexterity. This presence and influence of the modernistic paradigm is not overtly acknowledged in the ambidexterity literature but it is extensive and has important implications for the way in which the literature has been shaped.

Modernism, and its kindred scientific experimentationalist methodology of positivism, have constituted the dominant philosophy over much of organization and management during the last century (Alvesson \& Willmott, 1996; Willmott, 2005; Linstead, Fulop, \& Lilley, 2009; Clegg et al., 2011). Modernism and positivism subscribe to values of rationalism and objectified knowledge and are underpinned by principles and approaches that frequently represent knowledge 
in the form of, inter alia: binary and dualistic categorizations of phenomena (i.e. reductionism); metrics and linear representations of processes (i.e. linearity); clear delineations of phenomena possessing apparent clear boundaries; and, the privileging of the centrality and appropriateness of managerial control (i.e. categorization, quantification and representation) (Lyotard, 1984; Dereli \& Stokes, 2007; Stokes, 2011). Relating modernism to organizational ambidexterity, it becomes possible to discern and recognize a number of shared resonances. These include, as alluded to above, the initial dualistic representation of 'exploitative' and 'explorative' delineations. These can be argued as working constructs attempting, in a generalized way, to encapsulate multi-faceted and complex contexts and dynamics (i.e. reductionistic causality - see for example Rothaermel and Alexandre (2009) and McClean and Collins (2011)). In fact, causality rather than being a simple question of one variable on another is often better understood as complex and involving interaction of multifarious factors. In a similar vein to reductionistic commentaries on causality, many commentaries on organizational ambidexterity employ further generic concepts of, for example, 'effectiveness', 'heightened performance’ and 'competitive advantage' (see for example Jin et al., 2010 and Yang \& Li, 2011) to describe conditions and effects in macro-organizational situations. This leaning towards generalized and macro-concepts and working terms is particularly reflected in a dominant focus on the overall entity - and particularly corporate entities - combined with a privileging of the study of 'top management teams' as opposed to more individual and wider employee accounts. At a further level, the above delineations invoke assumptions around the identification of boundaries (i.e. representation) ‘othering' (or alienating) effects. In other words, for example, some individuals may experience stronger adherence to exploitive modes or organizational ambidexterity while 'othering' explorative modes and those individuals who espouse these modes. Moreover, in tandem with such 'othering' stances a focus of the above 
macro-predilections has often been to the exclusion of the discursive 'granular' microcomplexities of the interaction and cross-over between exploitative and explorative spheres and the role of the non-managerial employees and individuals. Thus, intra-organizational microdynamics are less evident in much of the organizational ambidexterity literature (Russo \& Vurro, 2010). While much progress has been accomplished on organizational ambidexterity within the current frames of reference, there is nevertheless scope to consider to a greater extent some of the less commented aspects of the field. In order to achieve this, previously under-explored ('othered') methodological approaches can also be adopted and this resonates with the call from Junni, Sarala, Tras, \& Tarba, (2013) who suggest that a broader range of methodologies should be utilized when investigating organizational ambidexterity. A concern regarding the role of modernism leads to proposition 2b:

Proposition 2b: To reveal modernistic dimensions and effects of organizational ambidexterity which are under-commented.

\section{Applying Critical Approaches to Organizational Ambidexterity.}

In contrast to modernistic approaches, critical paradigms provide an alternative perspective to modernism and an interesting vehicle with which to consider micro-aspects of organizational ambidexterity. Reflecting this, Andriopoulos and Lewis (2009:104) indicate that innovation paradoxes, within the context of organizational ambidexterity, necessitate paradoxical management approaches. Emerging largely in the late twentieth century and early twenty-first century, critical perspectives offer insights from postmodern and poststructuralist-informed paradigms and styles of presentation in attempts to supplement and complement extant understanding and sense-making in relation to organizational life (Alvesson \& Willmott, 1996; Spicer, Alvesson, \& Karreman, 2009; Wisser, 2010). Building on critical literature, one study 
examined how paradoxical approaches might help creative workers to cope with competing identity demands (Gotsi et al., 2010).

Critically-orientated inductive paradigmatic approaches to understanding organizational dynamics tend to urge caution over the 'othering' consequences of representation. In other words, they suggest that any term (be it 'innovative', 'learning', 'exploitative’, 'explorative’ or any other) creates potential boundaries and effects. Furthermore, reductionism, while providing a prima facie valuable tool, also risks over-simplifying complex domains with artificial boundaries that weakly reflect individual lived experiences (Knights \& Willmott, 1999). There is therefore scope to develop a less managerialistic (i.e. senior management team - centric) accounts of organizational ambidexterity and, alternatively, consider everyday exchanges and interactions. Exploration of qualitative data has the potential to provide a fine grained analysis leading ultimately to a clearer understanding of macro-organizational ambidextrous environments (Simsek, Heavey, Veiga, \& Souder, 2009).

While explorative aspects of organizational ambidexterity are also commonly treated within a modernistic approach, herein, interestingly, there are nevertheless many of the features kindred with critical concerns. These include for example: emergent learning, innovating novel domains, the perception and acquisition of remote and imperceptible knowledge and events (as opposed to known and residual knowledge, extant domains, proximate and perceivable knowledge and events). All of these are strongly associated with more critical, rather than modernistic, ways of looking at organizations. Therefore, it would seem that the underlying features of explorative aspects of organizational ambidexterity align more naturally with more critical organizational paradigms. These critical approaches have pointed ways towards more explorative-style approaches characterized by discontinuous, fragmented, discursive and rhizomatic patterns of 
organizational design and behavior. It can be seen that many of these traits readily align with the fluidity and flexibility of explorative modes of organizational ambidexterity and that they has the potential to provide a vehicle with which to progress towards a reconciliation of these differing paradigmatic positions. We can thus see that organizational ambidexterity, with its simultaneous interface, yet juxtaposition, of exploitative and exploratory states, provides a compelling nexus of not only exploitative and explorative pre-dispositions, conditions and states but also paradigms. Such notions of simultaneous contradictions or operations of exploitative and exploratory behavior, combined with ways of talking about organizations along the lines of ambidexterity, evolutionary or chaotic patterns, are evidently some distance from what is widely seen as a more normative modernistic representation of organizations (see discussion by Stacey, 2012; Breslin \& Jones, 2012; Clegg et al., 2011; Willmott, 2005; Knights \& Willmott, 2000). Within the above context, organizational ambidexterity thus presents itself as a variable dependent on, and determined by, the composite effect of socially constructed independent and operational variables of individual and group behaviors.

Moreover, critical approaches inductively consider the possibility of multiple potential meanings surrounding issues and contexts embracing identity, discourse, power and sense-making (Jermier, Knights, \& Nord, 1994; Weick, 1995, 2009; O’Leary, 2003; Brown, 2006) evident in organizational life and commonly played out at the micro and individual level. Micro-moments provide a means through which the dynamics at individual level of moving from exploitative to explorative states might be examined. The notion of the 'micro-moment' has attracted consideration in popular and wider media and contexts (Roan, 2009). Much of this points up the importance of the immediacy, local nature and individual siting of 'moments' kindred with Hill and Birkinshaw’s (2012) notions of exploitative ‘proximity’ in ambidexterity. Wider management 
writing too, has connected to some extent with 'moment' concepts and among these perhaps one of the better known is the commentary by Carlzon and Peters (1989) in relation to 'Moments of Truth' here focusing on achieving high quality customer service by reflecting on micro-moments of client interaction including, for example, 'When we talk to a customer on the phone..... When a customer returns a product' etc. Moreover, Shaw (2010), from a coaching perspective, points at the significance of identifying 'Defining Moments' in individual's lives. Within the present argument, micro-moments underline the myriad interactions and fleeting events of the everyday. In turn, these ultimately coalesce into macro-atmospheres and overall situations and overall cultures. Micro-moments are comprised of the panoply of human behavior and emotions: selfishness, unbridled ambition, politicking, disingenuousness juxtaposed and balanced in relation to ideas of hope, goodness, honor, wisdom and truth (Kessler, 2007; Mills, 2010; Michelson, van Iterson, \& Waddington, 2010). At the instant of these moments how people choose to act and respond is critical.

In summary, a closer consideration of independent variable micro-level individual behavioral issues and moments and their causal impacts on organizational ambidexterity will assist in better understanding how macro-organizational effects and cultures are caused and produced. The turn towards the micro goes hand-in-hand with a turn away from the macro. In relation to organizational ambidexterity, this translates the micro into the intra-firm issue rather than the totality of the firm working as a unit of analysis and comparison with other firms or units. The intention of the present argument is to complement the extensive work already conducted within the area of organizational ambidexterity (Gupta et al., 2006). The above argument leads to:

Proposition 2c: The argument will develop focused and detailed critical perspectiveinformed data from an intra-organizational as opposed to (within a majority of organizational ambidexterity writing) the more prevalent inter-firm comparative study. 


\section{'Lived Experience’ on the Boundary of the Ambidextrous Balance.}

A key challenge for individuals working in organizational ambidextrous contexts of contemporary firms is the need to be able to understand, reconcile, accept and even embrace simultaneous and interactive divergent and convergent effects of organizational ambidextrous settings. In other words, these involve the undertaking of sensemaking processes (Weick, 1995; Knights \& Willmott, 1999) and the development of mind-sets that can synthesize exploitative and explorative elements of ambidexterity in order to accomplish transitions in organizations. Knights and Willmott (1999) cast lived experience as ways of discussing organizational life that are fullblooded and visceral experiences enveloped by their sea of human actions and perceptions. They contrast this view with the normative modernistic and managerialistic representations of organizations that discuss people merely as conduits to achieving heightened organizational performativity. Alternatively expressed, it is important to understand how individuals approach and move across boundaries of exploitative and exploratory organizational elements of organizational ambidexterity. It was outlined in the argument above that many aspects of organizational ambidexterity literature exhibit modernistic traits. And, whether managers and other employees implicitly or explicitly acknowledge it, they are charged with gauging, responding to, coping with and even, in many instances, nurturing the transition from the modernistic to the critical dimensions of organizational ambidexterity. This challenge may be potentially inherently problematic for some management mind-sets (Nemanich \& Vera, 2009). This will particularly be the case with those individuals who are familiar and comfortable operating only in a 'known' and ‘predictable’ exploitative mode. 
From the intellectual capital perspective, scholars identified the importance of HRM practices in achieving organizational ambidexterity. Turner and Lee-Kelley (2012) identified social, human, and organizational factors that constitute the underlying mechanisms for achieving exploration and exploitation. In the context of law firms' practice groups, option-based HRM enables exploratory and exploitative learning (Kang, Snell, \& Swart, 2012).

In the change event of mergers and acquisitions, HRM practices play an important role influencing the performance (Weber \& Tarba, 2010). For example, the autonomy of the acquired firm can significantly affect top management retention (Ahammad, Glaister, Weber, \& Tarba, 2012). Training and communication may largely alleviate the cross-cultural conflicts during mergers and acquisitions (Weber, Rachman-Moore, \& Tarba, 2012). The 'developmental', 'remote’ and ‘unpredictable' challenges (Hill \& Birkinshaw, 2012) presented by a transition to explorative modes can create serious difficulties for individuals whose ‘comfort zone' resides primarily or uniquely in exploitative modes. Typical challenges might include, for example: realignment of scarce resources between disparate exploitative and explorative activities leading to tensions and conflict; the blurring of roles as new responsibilities are reconfigured or allocated to take on explorative activities; adjustment of traditional and conventional exploitative organizational boundaries in order to respond to new explorative environments; or, challenging and modifying entrenched practices and organizational cultures and sub-cultures. Essentially, explorative experiences often mean moving from the ‘known' to an 'unknown' new world full of uncertainty. Individuals therefore are obliged to look for ways to create meaning in their new environment(s).

The argument therefore proposes to develop data which illustrate the paradigmatic tensions that reside within organizational ambidexterity. In so doing, it draws on critical perspective 
approaches that surface the lived experience, micro-moments in a particular (under-researched) intra-organizational context. The ultimate purpose is to make a contribution to a better understanding of the micro-dimensions at the exploitative and explorative boundary and interface of organizational ambidexterity. Consequently, this produces the final proposition of the argument:

Proposition 2d: The argument will portray hitherto obscured data of individual lived experience in relation to organizational ambidexterity.

\section{Methodological Approach}

The field research took place between 2010 and 2012 in a quasi-public training and development organization located in the United Kingdom. Adoption of a single organization case approach enabled an examination and interpretation of organizational ambidexterity in an intraorganizational context (Flick, 2009; Yin, 2009). Moreover, while this organizational setting implicitly involves aspects comparable with corporate life (profitability, targets, performance issues etc.) and therefore has relevance for corporate contexts, it also provides insight into a slight variation, and original contribution, on the usual organizational forms examined in the organizational literature.

The data were gathered using an ethnographic and interpretive approach. This reflects Junni et al., (2013) concern on a need for a greater variety of research methodologies in the study of organizational ambidexterity. It employed participant observation and unstructured interviews with 80 participants comprised of 9 managerial staff and 71 operational and administrative staff (Van Maanan, 1988, 2010; Knights \& Willmott, 1999; Waddington, 2004; Delbridge \& Kirkpatrick, 1994; Maylor \& Blackmon, 2005; Eriksson \& Kovalainen, 2008). The selected population constituted all the employees of the organization. All participants were engaged in the study. These forms of methods was selected because they facilitated an in-vivo lived experience 
data collection approach that encouraged participants to recount or 'tell their own story' and thereby provide a more comprehensive understanding of the participants' 'world(s)' (Bryman and Bell, 2003: 477; Barbour \& Schostak, 2005: 42-44; Polonsky \& Waller, 2005: 131; EasterbySmith, Thorpe, \& Lowe, 2008, 88; Gray, 2009: 373; Czarniawska, 1998; Gabriel, 2000, 2004). This approach is well suited to a 'granular' exploration (Raisch \& Birkinshaw, 2008:401) of the boundaries between exploitative and explorative modes of organizational ambidexterity and the operation of individual behavior and micro-moments. Additional data were drawn from a range of documents including organizational meetings and email exchanges which supplied 'moments' and context (Flick, 2009:255; Gray, 2009: 428; and Bryman and Bell, 2003:566; Prior, 2003).

All of the data were subject to analysis via processes of template analysis (King, 2004). This allowed prevalent themes, issues and narratives to emerge and crystallize (Berger \& Luckmann, 1966; Weick, 1995; Czarniawska, 1998; Watson \& Harris, 1999; Knights \& Willmott, 1999; Gabriel, 2000, 2004). Validity and reliability were monitored through study meetings and exchanges and all participants and organizations have been anonymized in order to protect confidentiality.

\section{Presentation of the Field Research Context}

The organization was one within a group of companies operating under a quasi-public holding group-type structure. The organization serviced an extensive and varied client base. While there were certain corporate dimensions and processes within the organization, the research sought to develop fresh data in two regards; firstly an alternative to the frequent presentations of corporate environments and their senior management teams; and, secondly a focus on individual behavior and the micro-dimensions at 'granular' level in the boundaries between exploitative and explorative modes of organizational ambidexterity. An examination of individual context in a 
quasi-public setting provided this response. The study focused on a quasi-public institution for a number of reasons. First, the trend of professionalization in non-profit organizations (Hwang \& Powell, 2009) means that the (quasi-)public organization shares the commonalities with organizations in the commercial sector. Second, this transition in various sectors is an enduring topic across different types of organizations, including public service sector (Vince \& Broussine, 1996).

The study concerns an organization facing a turbulent market environment presenting many challenges including, among other issues, new product demands from its existing client base; the development of international markets, and, skills shortage among the team. The membership of the management group of the organization had recently been changed by the directorate in response to poor income streams and a perceived sense that the organization was not sufficiently dynamic for its evolving environment. For a number of years the organization had made progress in its markets, however, a number of the operational staff had got themselves into what was widely described as a 'comfort' zone (Andriopoulos \& Lewis, 2009:110). This meant that the essential tasks allotted were being achieved and the main body of staff were professional in their own right. However, whilst 'going the extra mile' or 'doing what it takes until the job is done' might be considered a standard maxim in many professional contexts, there was not always a widespread sense of this in the organization. Equally, many individuals had allowed continuing professional development activities to fall by the wayside and much of the workforce had consequently become relatively under-skilled to industry-sector norms. The situation in the observed case reflected the observation reported in Raisch and Birkinshaw (2008:377): 
'A one-sided focus on exploitation may enhance short-term performance, but it can result in a competency trap because firms may not be able to respond adequately to environmental changes'.

The newly appointed managers were either completely new or relatively recently appointed to the organization from existing roles. Most of these managers had arrived with a considerably higher level of experience and expertise than was commonly the case in the organization. While the change was initiated by a directorial level team the employees, at all levels, within the area were very much left to work through the adjustments and interplay of exploitative and explorative issues and challenges (Gupta et al., 2006). In this way it was very much a situation experienced in the micro- , or at the very least, small group situation.

The main body of professionals working at the operational level engaged in a range of behaviors and perspectives on the changing situation. As might be expected in any change situation, a number of the individuals were keen to maintain the status quo in relation to working practices and exhibited reluctance to engage in ideas and actions in relation to change. Another, smaller group (some twenty per cent of the workforce), welcomed the possibility of undertaking new challenges and working with new approaches. A further sizeable group (approximately seventy per cent) seemed potentially enthused by the possibility of change but also remained wary and cautious and adopted something of a 'watching and waiting' stance. A very few individuals were characterized by various members of the organization as being 'on their own planet' and seemingly oblivious to the on-going and inevitability of the changing situation around them. These were also typically acknowledged by many colleagues as being among the most disengaged members of the organization. 


\section{Findings and Discussion: Individuals, Micro-moments and Boundaries in Organizational Ambidexterity in an Intra-Organizational Context}

From the data analysis (King, 2004) a range of themes emerged in relation to the study’s research question which it will be useful to reiterate at this point:

What are the types, forms and conditions of localized, individual, behavioral and structural actions and processes that shape organizational ambidexterity at the boundaries of exploitative and explorative modes in intra-organizational contexts?

\section{Organizational Ambidexterity as a Quasi-Public, Intra-Organizational Experience.}

The literature review has identified that many studies in the organizational ambidexterity field have undertaken comparative inter-organizational examinations rather than considering intraorganizational cases. This study contributes to the literature by making such an intra-organizational case and, moreover, with regard to the span of sectors already studied in organizational ambidexterity, this piece of work considers a case from the under-examined area of quasi-public sector. Furthermore, overall and aligned to the material developed in the literature review, the findings are conducted through a critical perspective lens that identifies and acknowledges the hegemonic role that modernism has hitherto exerted on the field of organizational ambidexterity.

From the data gathered there was evidence that the behavior of the extant (rather than new) management team and many of the wider employees followed precepts akin to exploitative modes grounded on modernistic thinking (i.e. reductionistic thinking, causality and linearity of action, and, managing through metrics and numbers). Moreover, these were also the characteristics that underpinned much of the delivery of their training development repertoire. Generally, only training that reinforced these aspects was promoted in the old-style and pre-transition organization. On the other hand, as aspects of the organization began to change, more critical and explorative 
perspective approaches and behaviors were also on display as some employees discovered a heightened value in developing explorative stances and constructed new and emerging professional identities in the emergent environment. Nurturing individual competencies can foster intra-organizational change initiatives in the context of corporate entrepreneurship (Hayton, 2005; Hayton \& Kelley, 2006). This has been alluded to, in part, through the notion of 'integration mechanisms’ within in organizational ambidextrous settings (Jansen, Tempelaar, Van den Bosch \& Volberda, 2009). Such mechanisms can be management driven or may also occur at between individuals at interfaces between teams. Top management team behavior integration, such as information sharing, collaboration, joint decision making, can cultivate behavioral complexity that leads to organizational ambidexterity (Carmeli \& Halevi 2009). In the case under examination, these changes were negotiated and explored through various discursive practices and symbolism. For example, much of this sensemaking (Weick, 1995) was conducted in the usual 'coffee', 'corridor', 'water cooler', 'washroom' moments and situations (Stokes \& Harris, 2012; Shaw 2010). Sensemaking and reframing were identified as important mechanisms for middle managers to interpret change as firms move toward more decentralized structure (Balogun \& Johnson, 2004). In working through paradoxical challenges in the midst of organizational restructuring, middle managers' sensemaking may facilitate the process of constructing a workable certainty that enables change (Lüscher \& Lewis, 2008). Equally important were email exchanges challenging for and seeking to build new exploratory-style spaces. This involved, for example, the setting up of a social association. A ‘yoga club’ was its first club and this was very much seen as an (explorative) selforganizing initiative (Dyer \& Eriksen, 2005) as it revealed an 'art of the possible’ in the changing environment. However, it should be remembered that while these actions involved collectives, the site of these ambidextrous actions within the organization was, in large part, evidenced as 
ultimately the transformation and exchange that was taking place within the individual(s). This highlights the critical aspect of the micro-dimensions of lived experience and the role the many ‘micro-experiences’ play in constructing the ‘macro’ impression.

Moreover, within the change processes taking place it was possible to discern what can be described as effectively two movements that seemed to be operating in processes that reflect organizational ambidextrous patterns. These spheres can be characterized respectively as an expansive movement and a constraining movement. Within the terms of organizational ambidexterity discussed above, it was possible to discern both exploitative and explorative traits and elements in each of these spheres of action. This resonates with the notion of stability and change as a duality in an ambidextrous organizational setting (Farjoun, 2010). A recent study proposed a process-level theory that postulates organizational structure as a determinant of achieving organizational ambidexterity (Csaszar, 2013). However, in general, it was possible to identify alignments primarily between exploitative patterns and constraining movement and, then again, alignments principally in organizational ambidexterity explorative patterns and expanding movements. These spheres of operation seemed to be set in motion most commonly through email communication and large group meetings. The expansive movement was overtly postulated by the management as a novel 'opening up' or 'liberating' sphere. This meant that those individuals who felt or believed that they had been restricted or limited in some way by the previous culture could now be afforded the opportunity to embark on new projects, renewed self-development and the development of new products within the organization. This is not to suggest that the existing organization was devoid of innovation or creativity in its previous periods of development but there was a sense that the status quo towards exploitative modes had been over-emphasized and over-privileged in the past. In this way, the extant organization exhibited strong modernistic and 
positivistic sense-making characteristics aligned with representation, causality and linearity. As part of this the organizational vision was objectified and did not allow for alternative subjectified perspectives. This informed Proposition 1 and identified the conservative and, in organizational ambidextrous terms, the exploitative prone nature of the quasi-public organization.

The expansive movement represented a combined set of principles, atmospheres and actions that embraced, for example, spirits of entrepreneurialism, optimism, self-development, teamwork, growing together and building. Overall, this movement might be characterized as exuding a sense of excitement, energy positivity for a small minority (twenty two per cent) of employees. For others, who had blended with the status quo it could appear threatening and concerning. For a majority of respondents there was clearly an issue about where their 'place' now was in the changing organization. An employee connected to exploitative behaviors commented to an employee engaging with more exploratory and expansive modes stated:

'You're the future of this organization - I am its past and history' (Respondent 6).

Alternatively, reflecting the notions of 'agility' outlined by Shafer et al., (2001) a small group and minority of employees saw the interaction at the boundaries of the exploitative constraining movement and the explorative expanding movement positively:

It's great, it's all happening. There is a really great vibe and a sense that things are getting a grip of and lots is possible (Respondent 15).

(Herein, it is significant to note that the commonly recognized terminology of organizational ambidexterity espoused in the literature was not openly or overtly employed by 
individuals in the organization.) This expansive explorative movement of organizational ambidexterity was supported by resource investment in terms of time allocated and funding made available for developmental activities and projects. This was seen by many as an act of approbation by senior management. However, a majority of respondents, having a propensity to reside in the exploitative status quo, indicated that they viewed this as a focus on some novel and new activities of the organization's business at the expense of some of the longstanding and traditional activities.

In many regards both these above forms of behavior cast interesting light on exploitative and explorative dimensions of organizational ambidexterity. From an exploitative perspective, it was evidenced that there were competing efforts in different quarters. On the one hand, some twenty-five per cent of employees were eager to explore the roles and resources that were present in the organization and begin to envisage ways to redesign and reconfigure them. Alternatively, other employees (approximately forty per cent) more rooted in exploitative modes stated:

'Everything is working fine, we don't see the value of the changes and new approaches we should keep everything the same' (Respondent 62).

Moreover, more recently appointed managers attempted to encourage existing managers not to conduct themselves, or function, in what had been the previous constructed, acculturated and predominant managerialist mode or modernistic mind-set (Berger \& Luckmann, 1996; Weick, 1995). This produced an interesting tension because, whilst some members of the organization were keen to embrace the more 'expansive' and exploratory aspects of the new regime, others felt committed to residing and maintaining the original environment. Paradoxically these managerialist tendencies worked well in a number of specific aspects of the constraining movement (or the exploitative constraining dimensions) - for example, in terms of routine operational issues such as 
controlling, optimizing and even 'policing' new procedures on booking holiday and staff development. However, such constraining exploitative managerialist behaviors were less conducive to some of the explorative and expansive aspects, for instance, liberalizing resources, new product development and reassigning employees to new projects. A middle manager's managerialistic and power exerting statement to an employee engaging in new activities and behaviors revealed the paradoxical interface of these exploitative and explorative modes:

'Oh but you can’t do that new skills training course for yourself - you haven't got time to do that. You've got all your existing projects to get done’' (Respondent, 31)

Drawing on the organizational ambidexterity literature discussed above, these new challenges might prima facie be characterized as requiring innovative exploitation, i.e. rearranging internal cultures, structures resources and, importantly, discourses, whilst a range of challenges and novel client bases relating to new and emerging training markets required innovative exploration (Bierly et al., 2009). Clearly, within such settings there were potential tensions and conflicts relating to these oscillating convergent and divergent needs and the reconfiguration of organizational resources. Individuals and groups at all levels across the organization needed to reconcile this by implicitly enhancing, what were in effect, the ambidextrous aspects of the organization. However, as indicated above, this frequently had to be accomplished, by individuals, at the boundary or site of confluence of exploitative and explorative events and moments. In essence, these moments of reconciliation at these boundaries of organizational ambidexterity created tensions and paradoxes. 
As a deliberate intra-explorative act (i.e. within the organization) the organization management set up 'Innovation Teams'. These operated on a self-organizing basis and also established their own remit (Stacey, 2012; Dyer \& Eriksen, 2005). These groups operated within the managerial reporting structure of the organization but were given support, license and a guarantee that projects would be embraced and taken forward in some shape or form. These groups were encouraged not to dedicate too much time to formal meetings and that it was imagined that it would be possible to develop a wide range of exchanges and conversations through email. The team's initiative formed part of the exploratory actions. A number of individuals willingly engaged with these groups. Nevertheless, juxtaposed to such volunteerism was a reticence and 'biding time and watching' approach by others:

'Well let’s see how it goes and then we'll see what happens next' (Respondent P).

In many ways, this form of statement echoed the stable and fixed acculturation of the modernistic setting and was simultaneously wary of the expansive, explorative critical possibilities that lay ahead. The email aspect of this initiative was interesting in that, set against the usual recognizable maelstrom of email in most organizational contexts, it was valuable to see the potent role of email in negotiating, understanding and building organizational ambidexterity. Email exchanges became the site of sensemaking (Weick, 1995) in relation to the exploitative and explorative aspects. It was interesting to hear reports of a range of various tactics being employed to argue and sway opinion across emails. This, of course, involved commonly employed political tactics such as the 'copy all' device. While email was not the central focus of the study, due to the limited access to these media, it is nevertheless useful to keep in mind the role of electronic and social media on the shaping of organizational ambidexterity. 
In addition, the organization engaged a network of associate advisors and consultants allies and friends who were approached with a view to introducing and developing an embryonic coaching culture into the organization following Jansen et al. (2008). A further advisor facilitated keynote discussions and internal seminars on notions of fluidity and flexibility at work (Jin et al., 2010). This focus on agility and balancing tasks was reflective of the explorative dimensions of ambidexterity that were being highlighted in the organization (Dyer and Eriksen, 2005; Shaw, 2012). It also pointed at the value, need and desire of staff to move between the exploitative and exploratory aspects of learning and the need, with the latter in particular, to develop and embrace fresh ways of thinking and paradigms.

\section{Exploitative Inertia.}

Exploitative inertia can be argued as being a product of the modernistic characteristics discussed in the literature review sections 'Exploring the Role of Modernism in Organizational Ambidexterity and its Limitations'. Therein, the modernistic mindset, in contract to a critical perspective approach, makes sense of environments through values of representation, categories, fixed boundaries and notional objectivity. These can marry well with the known, predictable and stable traits often ascribed to exploitative aspects of organizational ambidexterity. Alternatively, from a critical perspective view such 'fixedness' and stability is seen as an illusion in the realities of dynamic unknown, unpredictable and ever-shifting, meanings, environments and identities or organizational settings. Explorative dimensions of organizational ambidexterity reflect these dimensions well.

The research identified a range of behaviors that were associated with commonly identified reluctance to embrace change of the new environment. In particular, a number of managers showed 
a great reluctance to modify anything very quickly. Many individuals in the organization observed these behaviors and took their cue from them showing the power of influence that this lead might impart. A significant number reported that this was largely because, in the early phase of transitions, they were unsure whether the change would be sustained by the new management and therefore they would adopt a 'wait and see' approach. In line with Raisch and Birkinshaw (2008) this acted as a substantive moderator on the enactment of organizational ambidexterity. However, this behavior was also linked to other behaviors. For example, many of the respondents had not self-developed substantially over a number of years preceding the change. This induced a great fear that they did not have the appropriate skill set in order to conduct the novel roles that would now be expected of them. A previous study highlighted the importance of organizational members' emotions and relations in the context of organizational change in the United Kingdom public service sector by elucidating the paradoxical emotions of individuals during the process of change (Vince \& Broussine, 1996). In effect, a new approach to exploitative behaviors would be required. This paralysis in front of the changing exploitative situation was thus characterized by a combination of fear, waiting, passive resistance, waiting for new leadership to demonstrate and establish its authority. This echoed Chermack et al., (2010) concerns that movement from exploitative to explorative states in organizational ambidexterity requires preconditions of psychological safety and clarity. It is suggested shared leadership, such as cooperative conflict management style and decision-making comprehensiveness, as an important enabler of organizational ambidexterity (Mihalache, et al. 2014). As one employee said to a new manager:

'We'll wait to see what happens' (Employee, 29).

In this way it can be said to constitute a form of 'exploitative inertia' within the organizational ambidextrous environment. This means that employees continue to work in a 
relatively low-key and cautious manner and, as one employee said 'ticking over' in the same and usual pattern of work behavior. Interestingly, exploitative inertia exhibited not only in the negative and resistance patterns (Jermier et al., 1994) described above but was also accompanied by a positive set of narratives that operated to justify the exploitative inertia. Typically these were of a celebratory and self-congratulatory nature independent of alternative opinions on the reality of the situation:

'We are doing very well’ (Respondent 55).

'Staff here work very hard' (Respondent 32).

These narratives generally contended that employees at the organization were 'innovative', 'hard pressed', and 'very busy'. Ironically, this commentary was accompanied by staff being stated by other staff as 'disappearing' and 'not being around' during quieter times in the office. Furthermore, the exploitative inertia was characterized by a tendency to cast and conduct the extant work activity in a very functionalistic and modernistic manner (Clegg et al., 2011). It was made very clear by some middle managers that the delivery of existing product through current training and development courses was the most important activity. The explorative development of new initiatives was initially actively discouraged by a majority of respondents:

'Initiative ' $\mathrm{X}$ ' is $\mathrm{b}^{* * * * * *} \mathrm{t}$ - forget it, don't waste your time' (Respondent 8).

There were also moral and ethical aspects to this part of the process because the fact that some individuals were, citing popular 'corridor' and 'water cooler' type conversations - 'getting away with blue murder' and were seen to be 'untouchable' or 'unmanageable'. This had a major impact on morale for a majority of respondents but produced uneasy and defensive reactions in others: 
'This is great that we are getting to grips with these longstanding issues' (Respondent 42).

‘Are you pinning all our bad performance on them?’(Respondent 13).

Across both the exploitative and explorative effects, a further simultaneous ambidextrous effect was witnessed in the manner in which existing structures and practices were sometimes incrementally adjusted through discussion and dialogues and, on other occasions, radically transformed by individuals. An example, of the former case was the way in which a protocol for client interaction was subject to intense email discussion, exchange and dialogue before the balance of opinion decided the matter. Our findings lend support to the argument that the informal organization can compensate the formal organization by motivating employee behavior based on a qualitative study investigating reorganization at Cisco Systems (Gulati \& Puranam, 2009). Nevertheless, not all employees seemed to agree and many had desired a more normative and modernistically regimented structure and membership of these meetings:

'We need a hierarchical set of aims and objectives on this' (Respondent 4).

However, on another question, regarding who should be allowed to attend client process meetings a managerial decision was taken. The purpose of the latter seemed to be an attempt to send out a signal regarding the principles that would operate in the organization and that these would be along the lines of transparency, openness and fairness and that these rose above all individual conjecture. The critical explorative postures were reflected in more colloquial expressions (following Andriopoulos \& Lewis, 2009): 
'It feels more freed up, more dynamic as if there is scope and possibilities to do things' (Respondent 12).

The potency of the phenomenon of exploitative inertia illustrates and underpins Proposition 2b: 'To reveal modernistic dimensions and effects of organizational ambidexterity which are under-commented.'

While exploitative inertia was identified in the quasi-public case (expectantly a traditionally conservative environment) this does not mean that exploitative inertia is uniquely restricted to, or the predilection of, quasi-public spheres. It is potentially feasible that corporate and wider sectors may also identify the presence of this phenomenon.

\section{Organizational Ambidexterity: Micro-Moments Within the Individual.}

The above argument has thus far sought to illustrate how critical perspectives can be readily aligned with, and indeed employed to critique certain, aspects of organizational ambidexterity. Following this overall argument, however in particular relation to the discussion above concerning 'Applying Critical Approaches to Organizational Ambidexterity', it is especially on the microlevel that critical perspectives can assist in accounting for experiences and transitions on and at the boundary of explorative and exploitative organizational ambidexterity.

As indicated above, the normative state in the organization for many individuals had been that of 'exploitative inertia'. As the new cultural change started to emerge it was interesting to observe how organizational ambidexterity operated at the individual level and, in particular, in the 
way that shifts occurred between exploitative and explorative states within the 'site' or 'locale' of the individual. This was not to deny the role of senior management teams in influencing action (Lubatkin et al., 2012); however, the data revealed a self-driven heightening of awareness in some individuals. Indeed, the change of management team had exerted some catalytic effects, but nevertheless, the role of individuals acting independently and in an explorative style (rather than in reactive or directly exploitative mode) was evidenced in a range of micro-moments. The instance of new product development and the identification of new markets provided a clear instance of exploratory activity, attitudes that produced revealing micro-moment statements. In earlier phases of the organizational culture these had been limited as 'too risky' and 'stretching existing resource'. These micro-moments portray a lived experience language (Knights \& Willmott, 1999) that, while illuminating organizational ambidexterity in action, is not the language in which organizational ambidexterity is expressed in the associated literature. Individuals talked about moving from exploitative to exploratory states and situations:

'It’s good to be involved in adding something new' (Respondent 37).

'Same old, same old is boring - it is great to be developing something and exchanging ideas' (Respondent 43).

The study observed organizational ambidexterity as a personal discursive process wherein individuals navigated and renegotiated their transition across a metaphorical bridge between exploitative and exploratory situations. This involved the action of choice. In this way organizational ambidexterity seemed to present itself as a process of taking power and control of immediate self. 
The change processes experienced were discussed in forms of narrative that reflected, for a majority of respondents, an opportunity to keep things relatively static or at best engaging in gradual emergence and incremental change (Linstead et al., 2009). This interacted, and at times conflicted, with a desire by other respondents to introduce some fluidity and multiple perspectives. These grounded exploitative behaviors were simultaneously accompanied by more tentative exploratory comportments in relation to which, on occasion, there was a sense of chaos-inducing actions by those seeking to challenge existing use of resources. This would take the form, for example, of calling meetings to discuss radical sounding agenda items or alternatively sending out a polite but 'provocation to debate' type emails in order to engender discussion, identify allies and set up new initiatives and terrain. This fluctuation across the boundaries of exploitative and explorative states echoes the notion of cyclical ambidexterity (Simsek et al., 2009). In relation to those respondents who had decided to fully embrace the exploratory postures of the newly emerging organization and culture there were also reports of personal micro-moments on journeys akin to 'awakenings' or 'personal epiphanies':

'I get it now - I know what to do I should be and how I fit in' (Respondent 2).

There was also some indication that earlier professional training played a role in informing these organizational ambidexterity sense-making narratives. It was commented by nine respondents that the employees who worked in human resource and marketing type roles and areas seemed to embrace explorative actions and developments more readily than those from, for example, finance and accounting backgrounds. The latter areas seemed more positivisticaly bound - rooted in their epistemological approach to marshaling knowledge. The data, therefore, suggested that moving from exploitative to explorative mind-sets can be difficult, particularly for some mind- 
set pre-dispositions. There were indications also that a degree of the impetus for individuals to move from exploitative to explorative behaviors was driven by career considerations. Thirty-four per cent of respondents indicated that they had career and professional ambitions and were frustrated by the over-emphasis on exploitative patterns in the organization. At this juncture, the discussion turns to inform two further earlier stated propositions:

Proposition 2c: The argument will develop focused and detailed critical perspectiveinformed data from an intra-organizational as opposed to (within a majority of organizational ambidexterity writing) the more prevalent inter-firm comparative study;

and;

Proposition 2d: The argument will portray hitherto obscured data of individual lived experience in relation to organizational ambidexterity.

This is a timely moment in the discussion to consider these two propositions in tandem. The discussion above manifests the presentation of critical perspectives in an intra-organizational context and the lived experience of the individual within that given context. The 'awakenings' of certain respondents illustrate as much as any other data the transformatory journey involved for the individual in moving across the exploitative and exploratory boundary. The movement from 'exploitative inertia' clearly presented a challenge but once the emancipatory action was taken towards a more radical explorative state a new vision and perspective was created by, and for, the individual. Indeed, Propositions 2c and 2d have been argued through the length of the discussion, however, it is ultimately when the major paradigmatic spheres interface: exploitative-explorative; macro-micro; modernistic-critical perspective, and more crucially when shifts between those interacting spheres occur that the individual in the micro-moment is confronted with choice that will determine and construct the macro-environment.

Paradigms and Micro-Moments as Mechanisms of Organizational Ambidexterity: A Synthesis. 
This final section of the findings and discussion develops a model from the data that shows the synthesis of exploitative and explorative dimensions at their boundaries. The model illustrates the normative-modernistic: critical perspective paradigmatic interface. It takes this forward by, firstly, outlining the broad and general conditions of organizational ambidexterity and, consequently, providing a series of states and conditions which exemplify this.

Organizational ambidexterity is quite often discussed as a dynamic and organic event. The study has pointed up the role and significance of micro-moments (Stokes \& Harris, 2012; Shaw, 2010). As discussed above, micro-moments represent the myriad instance in the course of the working day where a person engages within another person or persons. Every moment is a moment of truth and an opportunity to develop or diminish various aspects of relationships - trust, confidence, admiration, sharing and so on and so forth. Micro-moments point up the role of values, attitudes, beliefs and ethical stances in individual actions as people negotiate moves between exploitative and explorative postures. Senior managerial actions in the organization sometimes seemed to work as an 'other' against which people created their identity in such micro-moments. For sixteen per cent of respondents, it was more the case, that rather than taking their lead from certain senior managerial behavior (which they often viewed negatively), they characterized themselves as being different (and better) than senior managers.

'We know the right thing to do and we get on with it. Best to keep them [particular colleagues] out of the way as much as possible' (Respondent 36)

'We are not going to lower ourselves to that level' (Respondent 68).

Such micro-moment decision points and 'moments of truth' illustrated a taking of responsibility by the individual, or groups of individuals, for a transition from an exploitative 
condition to a more explorative state. The original, and now seemingly dated, exploitative patterns of behavior in the organization were being moderated in favor of new and emerging exploratory conduct. The emergence of these patterns of behavior could in no way be described as widespread. Instead, they operated more as 'organic pockets' or 'outcrops'. By this, it is meant that small groups of individuals would self-organize (akin to Dyer \& Eriksen, 2005) in order to take advantage of the opportunities of the new environment. In essence, this meant that individuals clustered in organic and seemingly (to the onward observer) complex and chaotic patterns in order to make sense (Weick 1995, 2009) of the emergent and exploratory environments.

The above emergent themes provide a valuable response to the research question posed above. Micro-moments and individual behaviors at operational levels can be seen to play a significant role at the boundaries of, and in the movement within, intra-firm organizational ambidexterity. It is certain that senior management team behavior is an influence and a factor that moderates this however the individual is a potent influence in his or her own right. Moreover, the study provides an opportunity to develop a representation of the paradigmatic and micro-moment principles identified as operating at the 'granular' boundaries in organizational ambidexterity within the research. Table I below aims to encapsulate this notion of exploitative and explorative action across boundaries and against a paradigmatic background. In its first section entitled (Foregrounding Conditions), the Table represents the over-arching operational principles observed at operation within organizational ambidexterity within the research field case (set in the context of the organizational ambidexterity literature). In essence, these embrace simultaneous yet juxtaposed states of complementarity and contradiction between exploitative and exploratory modes. They stand apart from each other across the boundary representation of the Table. 
These in turn are discussed (in relation to the preceding overall atmospheres) as Focal Boundary Conditions, in terms of the characteristics of exploitative and explorative states in relation to moments. Here the argument builds on the work and modeling of O’Reilly and Tushman (2004) who looked at the notion of the exploratory and the exploitative states of business and identified characteristics within them. The present discussion relates the oscillating interface of the two modes of organizational ambidexterity and turns the lens towards the intra-firm and individual situation while simultaneously relating them to the paradigmatic discussion conducted above.

The above table and overall preceding discussion responds and informs Proposition 2: 'Application of a critical perspective lens on organizational ambidexterity will be effective in identifying behavioral shifts from relatively conservative modernistic exploitative states to more radical critical explorative conditions' and its sub-proposition 2a: 'The micro-aspects of organizational ambidexterity will reveal the 'granular' dimensions of the phenomenon at the boundary of exploitative and explorative interaction and transitions by individuals between the two states and indicate how the micro creates the macro.' In conjunction with the overall preceding argument and data, it illustrates how individuals engage in a wide range of micro-moments at the granular boundary of exploitative and explorative transitions and make choices of transition, or not, based on a plethora of fleeting discussions, comments and encounters.

\section{Limitations and Further Research Implications}

The present study is inherently and explicitly limited to the consideration of a particular organization and setting. This was a deliberate intent of the paper as it sought to surface data from the operational employee level in an organizational context in relation to their experiences of 
organizationally ambidextrous environments. In turn, that the work concerns the focal sector of training and development and does not, naturally, directly concern wider sectorial interests. The research also expressly did not privilege a lens on the frequently studies senior management teams and strongly corporate environments as it had the aim of exploring wider employee experience at a micro-level and at the boundaries of exploitative and explorative modes of organizational ambidexterity. The intention to study an intra-organizational case also has implications for the generalizability. The paper concerns a single organization study in the interpretive and ethnographic methodological design tradition. This means that the results have validity in the context that they are established. The data findings and discussion have potential to be recognized as being relevant and valuable for other organizational settings depending on context. This will be achieved by the development of case and ethnographic accounts as part of future research projects.

In terms of practical implications and impacts there is a pressing need for managers and employees alike to develop abilities to be able to embrace blurring of boundaries between the current exploitative and explorative modes of organizational ambidexterity and the perceived inflexibilities and underlying dividing lines of modernistic and critical postures operant in within the phenomenon. It is in the recognition and understanding of these underpinning paradigmatic frameworks that a proper embracing of the exploitative and explorative modes of organizational ambidexterity resides.

With respect to HRM practices, it requests the space of freedom for individuals in the micro-moments context to experiment with new initiatives so as to enable the organizational change through a ‘bottom-up’ approach. Achieving organizational ambidexterity needs the art of ambidextrous leadership (Tushman, Smith, \& Binns, 2011) that can discern the possibilities attempted by individuals from below. The interplay between exploitation and exploration can 
fundamentally influence the process as well as deliverables in achieving sustainable competitive advantage. In essence, ambidexterity is about organizational survival and continuous innovation (O’Reilly \& Tushman, 2013). Our findings make important contributions to enhancing a more nuanced understanding of individual-level behaviors in the micro-moments context underlying the occurrence of organizational ambidexterity.

Moreover, further research which investigates the operation of organizational ambidexterity at the individual and operational group level (as opposed to primarily senior management teams) will be valuable. Intra-firm examinations are most likely to be conducive to this. As a consequence, as the work and understanding of organizational ambidexterity develops, it is the contention of the paper that there will be further scope for investigation and development of modernistic-critical dialectical approaches. The current paper provides a contribution to this. Importantly, our empirical study lends support to the argument that critical perspective can significantly contribute to social science (Delbridge, 2014), as illustrated by our ethnographical investigation on HRM and ambidexterity. In addition, it will become increasingly important to seek and secure the narratives of the individual across the spectrum of employees rather than privileging the voice of a particular managerial grouping. The findings confirm that the paradoxical rhetoric does indeed exist in reality and that all employees are seemingly creating some kind of sense-making process to appease this conflict. For management roles, this presents a significant challenge of deep-rooted complexity. Through further understanding of how organizational ambidexterity impacts on individuals, strategies can be built to accept the existence of this paradox as opposed to forcing upon employees either exploitative or explorative practices that can simply not exist in isolation. 
In conducting this work, the onus here also falls on academics, business schools, advisors, think tanks and consultants to recognize the powerful echo and legacy of the hegemony of a century modernistic shaping of thought and action and provide entrees and legitimacy for more critical insights. As a stage of developing this process there is a need for management to also become increasingly aware of the possibilities of switching between differing paradigmatic perspectives.

\section{Conclusion}

Ambidexterity is emerging as a variably subliminal, yet frequently explicitly experienced, paradigm of $21^{\text {st }}$ Century organizations. While still scarcely addressed in a range of areas of management literature, it offers itself as a useful account of the paradoxes and juxtapositions of modern/postmodern organizational life.

Hitherto this tension of paradigmatic views has tended to play itself out in terms of a normative-modernistic-managerialist discourse in broad competition for hegemony with a criticalpostmodern/poststructuralist-anti-managerialist narrative. This paper has argued that such a juxtaposition is potentially limiting. The notion of organizational ambidexterity, with its complex modes of exploitative and explorative operation and boundaries provides a sense-making device that represents the contexts in which contemporary employees and organizations increasingly themselves and between which there organizational lives and lived experiences ebb and flow.

In particular, the paper has provided timely and important focal data not only on the paradigmatic tensions and dialectics discussed above, but has also on an in-depth intra-firm situation. Moreover, these data move beyond the predilection of many studies for focusing on 'topteams’ and how they cope with organizational ambidexterity and, alternatively, considers a span 
of data from across many respondent-employees micro-moment situations. As indicated above, individual employees are a clear 'site' and 'locale' in relation to exploitative and explorative micro-moments and micro-patterns of organizational ambidexterity. Clearly, the consequences of the above feed into, construct, and interface with macro-cultures and actions in relation to macrofirm, senior management team actions and ultimately discussions on macro-modernistic concepts such as competitive advantage. To reiterate, Raisch et al. (2009:688) '....individuals’ ability to act ambidextrously will have a cumulative effect on the organization's ambidexterity'. As such they become a potent independent variable that drives and develops a consequent and dependent outcome of organizational ambidexterity at the intra-firm level and ultimately impact on the macro-firm and inter-firm operations.

Peter Stokes is Deputy Dean - University of Chester Business School, UK. He publishes in Organizational Behavior and Research Methodology. He is Editor-in-Chief - International Journal of Organizational Analysis, serves on a number of international journal boards and reviews for world-class journals. He manages international consultancy projects and is Vice-PresidentBusiness Relations/UK Country Director - EuroMed Research Business Institute and UK Ambassador - Association Francophone de Gestion des Ressources Humaines (French Academic HR Association). He is visiting professor to organizations and business schools in France, Holland, Spain, Ireland, Germany, Senegal (West Africa), Vietnam, Morocco, Hong Kong, China, India and Dubai.

Neil Moore is a Senior Lecturer at the University of Chester Business School. He teaches and consults in a range of business and management areas including international business, management development, contemporary issues in small and medium sized enterprises and sport management. His interest in business and sport led to his doctoral research into business management practices in the English professional football industry. He is currently a visiting lecturer and academic advisor in a number of HE institutions in the UK and overseas. He is also an Associate Editor of the International Journal of Organizational Analysis.

Danny Moss is Professor of Corporate and Public Affairs at the University of Chester Business School and co-director of the University's International Centre for Corporate \& Public Affairs Research. Previously he worked at Manchester Metropolitan University, and the University of Stirling, specialising in Public Relations, and co- founding the annual Global Public Relations Research Symposium held at Lake Bled, Slovenia. Danny Moss is the founding co-editor of the Journal of Public Affairs and has published in a wide range of journals and has authored a number of books, most recently Public Relations: A Managerial Perspective (2011) 
Martin Mathews is Senior Lecturer in Business Strategy at Westminster University. A former export manager he has worked in management positions at two French business schools and conducted consulting with a range of large OEM manufacturers. He has published on inter-firm trust and his research interests are centered on organisational change, proximities and knowledge.

Simon M. Smith is a Senior Lecturer in International Business within the Business School at the University of Chester. He is engaged in various research areas, including human resources, organizational behaviour, organizational analysis and business in higher education. He has been extensively involved in overseas presentations and project work in Spain and Germany.

Yi-Peng Liu is a Lecturer in Entrepreneurship at Kent Business School, University of Kent, UK. He earned a doctorate (magna cum laude) in Management from Mannheim University, Germany, and obtained professional education and training on Harvard Participants-Centered Learning methods (HBS-PCL) from European Entrepreneurship Colloquium. His research interests include international entrepreneurship, global talent management, and cross-border mergers \& acquisitions. His work is published/ forthcoming in Management International Review, Thunderbird International Business Review, International Studies of Management \& Organization, Prometheus, among others. Dr. Liu is a research fellow of Center for China \& Globalization, a global think-tank based in Beijing.

\section{References}

Ackermann, F., \& Eden, C. (2011). Making strategy: Mapping out strategic success. London, UK: Sage Publications.

Ahammad, M.F., Glaister, K.W., Weber, Y., \& Tarba, S.Y. (2012). Top management retention in cross-border acquisitions: the roles of financial incentives, acquirer's commitment and autonomy. European Journal of International Management, 6(4), 458-480.

Alvesson, M., \& Willmott, H. (1996). Making sense of management: A critical introduction. London, UK: Sage Publications.

Andriopoulos, C., \& Lewis, M.W. (2009). Exploitation-exploration tensions and organizational ambidexterity: Managing paradoxes of innovation. Organization Science, 20(4), 696-717.

Andriopoulos, C., \& Lewis, M.W. (2010). Managing tnnovation paradoxes: Ambidexterity lessons from leading product design companies. Long Range Planning 43(1), 104-122.

Balogun, J., \& Johnson, G. (2004). Organizational restructuring and middle manager sensemaking. Academy of Management Journal, 47(4), 523-549.

Barbour, R. S., \& Schostak, J. (2005). Interviewing and focus groups. In B, Somekh, \& C. Lewin (Eds). Research methods in the social sciences, 41-48, London, UK: Sage Publishing.

Benner, M. J., \& Tushman, M. L. (2003). Exploration, exploitation, and process management: The productivity dilemma revisited. Academy of Management Review, 28, 238-256. 
Berger, P.L., \& Luckmann, T. (1966). The Social Construction of Reality. New York, USA: Anchor Books.

Bierly, P. E., Damanpour, F., \& Santoro, M. D. (2009). The application of external knowledge: Organizational conditions for exploration and exploitation. Journal of Management Studies, 46 (3), 481-509.

Birkinshaw, J., \& Gibson, C. (2004). Building ambidexterity into an organization. Sloan Management Review, 4, 47-55.

Birkinshaw, J., \& Gupta, K. (2013). Clarifying the distinctive contribution of ambidexterity to the field of organization studies. Academy of Management Perspectives, 27(4), 287-298.

Boumgarden, P., Nickerson, J., \& Zenger, T.R. (2012). Sailing into the wind: exploring the relationships among ambidexterity, vacillation and organizational performance. Strategic Management Journal, 33(6), 587-610.

Breslin, D., \& Jones, C. (2012). The evolution of entrepreneurial learning. International Journal of Organizational Analysis, 20 (3), 294-308.

Brown, A. (2006). Organizational identity and place: A discursive exploration of hegemony and resistance. Journal of Management Studies, 43 (2), 231-257.

Bryman, A., \& Bell, E. (2011). Business research methods. Oxford, UK: Oxford Publishing.

Burton, R.M., Obel, B., \& De Sanctis, G. (2011). Organizational design: A step-by-step approach (Second Edition). Cambridge, UK: Cambridge University Press.

Carlzon, J., \& Peters, T. (1989). Moments of truth: New strategies for today's customer driven economy. London, UK: Harper Ltd.

Carmeli, A., \& Halevi, M., Y., (2009). How top management team behavioral integration and behavioral complexity enable organizational ambidexterity: The moderating role of contextual ambidexterity. Leadership Quarterly, 20: 207-218.

Cao, Q., Gedajlovic, E., \& Zhang, H. (2009). Unpacking organizational ambidexterity: Dimensions, contingencies, and synergistic effects. Organization Science, 12 (1), 781-796.

Chang, Y-Y., Hughes, M., \& Hotho, S. (2011). Internal and external antecedents of SMEs' innovation ambidexterity outcomes. Management Decision, 49 (10), 1658-1676.

Chermack, T.J., Bodwell, W., \& Glick, M. (2010). Two strategies for leveraging teams toward organizational effectiveness: Scenario planning and organizational ambidexterity. Advances in Developing Human Resources, 12 (1), 137-156. 
Clark, P.A. (1972). Organizational design: Theory and practice. London, UK: Tavistock Publications Limited.

Clegg, S., Kornberger, M., \& Pitsis, T. (2011). Managing and organizations: An introduction to theory and practice. London, UK: Sage Publications.

Csaszar, F. (2013). An efficient frontier in organization design: Organizational structure as a determinant of exploration and exploitation. Organization Science, 24(4), 1083-1101.

Czarniawska, B. (1998). A narrative approach to organization studies. London, UK: Sage Publications.

Delbridge, R., \& Kirkpatrick, I. (1994). Theory and practice of participant observation in V.J. Wass, \& P.E. Wells, (Eds), Principles and practice in business and management research. Aldershot: Dartmouth Publishing Company Limited.

Delbridge, R. (2014). Promising futures: CMS, post-disciplinarity, and the new public social science. Journal of Management Studies, 51(1), 95-117.

Dereli, C., \& Stokes, P. (2007). Reconceptualising modernity for management studies: Exploring the tension between the scientific and the spiritual in the age of modernism. Philosophy of Management, 6(2), 131-139.

Duncan, R. B. (1976). The ambidextrous organization: Designing dual structures for innovation. In R. H. Kilmann, L. R. Pondy, \& D. Slevin (Eds.), The management of organization, vol. 1, 167-188. New York, USA: North-Holl.

Dyer, L. D., \& Ericksen, J. (2005). In pursuit of marketplace agility: Applying precepts of selforganizing systems to optimize human resource scalability. Human Resource Management, 44 (2), 183-188.

Easterby - Smith, M., Thorpe, R., \& Lowe, A. (2008). Management research (Third Edition). London, UK: Sage Publishing.

Eriksson, P., \& Kovalainen, A. (2008). Qualitative methods in business research. London, UK: Sage Publications.

Farjoun, M. (2010). Beyond dualism: Stability and change as a duality. Academy of Management Review, 35(2), 202-225.

Flick, U. (2009). An introduction to qualitative research (Fourth Edition). London, UK: Sage Publications.

Gabriel, Y. (2000). Storytelling in organizations: Facts, fictions and fantasies. Oxford, UK: Oxford University Press. 
Gabriel, Y. (2004). Myths, stories and organizations: Pre-modern narratives for our times. Oxford, UK: Oxford University Press.

Gedajlovic, E., Cao, Q., \& Zhang, H. (2012). Corporate shareholdings and organizational ambidexterity in high-tech SMEs: Evidence from a transitional economy. Journal of Business Venturing, 27, 652-665.

Gibson, C. B., \& Birkinshaw, J. (2004). The antecedents, consequences and mediating role of organizational ambidexterity. Academy of Management Journal, 47 (2), 209-226.

Gotsi, M., Andriopoulos, C., Lewis, M. W., \& Ingram, A. E. (2010). Managing creatives: Paradoxical approaches to identity regulation. Human Relations, 63(6), 781-805.

Gramsci, A. (1971). Selections from the prison notebooks. New York: International.

Gray, D.E. (2009). Doing research in the real world (Second Edition). London, UK: Sage Publishing.

Greenwood, R., \& Miller, D. (2010). Tackling design anew: getting back to the heart of organizational theory. Academy of Management Perspectives, 24 (4) 78-88.

Groysberg, B., \& Lee, L. (2009). Hiring stars and their colleagues: Exploration and exploitation in professional service firms. Organization Science, 20 (4), 740-758.

Gulati, R., \& Puranam, P. (2009). Renewal through reorganization: The value of inconsistencies between formal and informal organization, Organization Science, 20(2), 422-440.

Gupta, A.K., Smith, K.G., \& Shalley, C.E. (2006). The interplay between exploration and exploitation. Academic Management Journal, 49, 693-706.

Han, M., \& Celly, N. (2008). Strategic ambidexterity and performance in international new ventures. Canadian Journal of Administrative Sciences, 25 (4), 335-349.

Hatch, M.J., \& Cunliffe, A.L. (2007). Organization theory (Second Edition). Oxford, UK: Oxford University Press.

Hayton, J. C. (2003). Strategic human capital management in SMEs: An empirical study of entrepreneurial performance. Human Resource Management, 42(4), 375-391.

Hayton, J. C. (2005). Promoting corporate entrepreneurship through human resource management practices: A review of empirical research. Human Resource Management Review, 15(1), 2141.

Hayton, J. C., \& Kelley, D. J. (2006). A competency based framework for promoting corporate entrepreneurship. Human Resource Management, 45(3), 407-427. 
He, Z., \& Wong, P. (2004). Exploration vs. exploitation: An empirical test of the ambidexterity hypothesis. Organization Science, 15 (4), 481-494.

Helfat, C.E., Finkelstein, S., Mitchell, W., Peteraf, M., Singh, H., Teece, D., \& Winter, S. (2007). Dynamic capabilities: Understanding strategic change in organizations. London, UK: Blackwell Publishing.

Hill, S.A., \& Birkinshaw, J. (2012). Ambidexterity and survival in corporate venture units. Journal of Management, Doi: 10.1177/0149206312445925.

Holmqvist, M. (2004). Experiential learning processes of exploitation and exploration within and between organizations: An empirical study of product development. Organization Science, 15 (1), 70-81.

Hwang, H., \& Powell, W.W. (2009). The rationalization of charity: The influences of professionalism in the nonprofit sector. Administrative Science Quarterly, 54, 268-298

Im, G., \& Rai, A. (2008). Knowledge sharing ambidexterity in long-term interorganizational relationships. Management Science, 54 (7), 1281-1296.

Jackson, N., \& Carter, P. (2007). Rethinking organisational behavior: A poststructuralist framework. Harlow: Pearson Education Limited.

Jansen, J. J. P., Simsek, Z., \& Cao, Q. (2012). Ambidexterity and performance in multiunit contexts: Cross-level moderating effects of structural and resource attributes. Strategic Management Journal, 33 (11), 1-18.

Jansen, J. J. P., George, G., Van den Bosch, F. A. J., \& Volberda, H. W. (2008). Senior team attributes and organizational ambidexterity: The moderating role of transformational leadership. Journal of Management Studies, 45 (5), 982-1007.

Jansen, J. J. P., Tempelaar, M. P., Van den Bosch, F. A. J., \& Volberda, H. W. (2009). Structural differentiation and ambidexterity: The mediating role of integration mechanisms. Organization Science, 20 (4), 797-811.

Jasmand, C., Blazevic, V., \& de Ruyter, K. (2012). Generating sales while providing service: A study of customer service representatives' ambidextrous behavior. Journal of Marketing, 76 (1), 20-37.

Jermier, J., Knights, D., \& Nord, W. (1994). Resistance and power in organizations. London, UK: Routledge.

Jin, Y., Hopkins, M., \& Wittmer, J. (2010). Linking human capital to competitive advantages: flexibility in a manufacturing firm's supply chain. Human Resource Management, 40 (5), 939-963. 
Johns, G. (2006). The essential impact of context on organisational behavior. Academy of Management Review, 31 (2), 386-408.

Jones, G. R. (2012). Organizational theory, design, and change: Text and cases. London: Pearson.

Junni, P., Sarala, S., Taras, T., \& Tarba, S.Y. (2013). Organizational ambidexterity and performance: A meta-analysis. Academy of Management Perspectives, 27(4), 299-312.

Kang, S.C., \& Snell, S.A. (2009). Intellectual capital architectures and ambidextrous learning: A framework for human resource management. Journal of Management Studies, 46 (1), 65-92.

Kang, S.C., Snell, S.A., \& Swart, J. (2012). Options-based HRM, intellectual capital, and exploratory and exploitative learning in law firms' practice group. Human Resource Management, 51(4), 461-486.

Kase, R., Paauwe, J., \& Zupan, N. (2009). HR practices, interpersonal relations, and intrafirm knowledge transfer in knowledge-intensive firms: A social network perspective. Human Resource Management, 48 (4), 615-639.

Kessler, E. (2007). Human, managerial and strategic implications, Group \& Organization Management, 31(3), 296-299.

King, N. (2004). Using templates in the thematic analysis of text. In C. Cassell, \& G. Symon, (Eds.), Essential guide to qualitative methods in organizational research. London, UK: Sage Publications, pp.256-270.

Knights, D., \& Willmott H. (2007). Introducing organizational behavior and management. London: Thomson Learning/Cengage.

Knights, D., \& Willmott H. (2000). The re-engineering revolution: Critical studies of corporate change. London, UK: Sage Publications.

Knights, D., \& Willmott H. (1999). Management lives. London, UK: Sage Publications.

Kostopoulos, K.C., \& Bozionelos, N. (2011). Team exploratory and exploitative learning: Psychological safety, task conflict, and team performance. Group \& Organization Management, 36 (3), 385-415.

Kouropalatis, Y., Hughes, P., \& Morgan, R.E. (2012). Pursuing “flexible commitment” as strategic ambidexterity. European Journal of Marketing, 46 (10), 1389-1417.

Kyriakopoulos, K., \& Moorman, C. (2004). Tradeoffs in marketing exploitation and exploration strategies: The overlooked role of market orientation. International Journal of Research in Marketing, 21 (3), 219-240. 
Lavie, D., Stettner, U., \& Tushman, M. L. (2010). Exploration and exploitation within and across organizations. Academy of Management Annals, 4: 109-155.

Levinthal, D.A., \& March, J.G. (1993). The myopia of learning. Strategic Management Journal, 14(S2), 95-112.

Lindblom, C. (1959). The science of "muddling through”. Public Administration Review, 19 (2), 79-88.

Linstead, S., Fulop, L., \& Lilley, S. (2009). Management and organization: A critical text. Basingstoke, UK: Palgrave-Macmillan.

Lubatkin, M. H., Simsek, Z., Ling, Y., \& Veiga, J. F. (2006). Ambidexterity and performance in small to medium-sized firms: The pivotal role of top management team behavioral integration. Journal of Management, 32: 646-672.

Lüscher, L. S., \& Lewis, M. W. (2008). Organizational change and managerial sensemaking: Working through paradox. Academy of Management Journal, 51, 221-240.

Lin, Z., Yang, H., \& Demirkan, I. (2007). The performance consequences of ambidexterity in strategic alliance formations: Empirical investigation and computational theorizing. Management Science, 53(10), 1645-1658.

Lyotard, F. (1984). The postmodern condition: A report on knowledge. Minneapolis, USA: University of Minnesota Press.

Mansfield, R. (1986). Company strategy and organizational design. London, UK: Routledge.

March, J. G. (1991). Exploration and exploitation in organizational learning. Organization Science, 2, 71-87.

Maylor, H., \& Blackmon, K. (2005). Researching business and management. Basingstoke: Palgrave-Macmillan.

McClean, E., \& Collins, C. (2011). High-commitment HR practices, employee effort, and firm performance: Investigating the effects of HR practices across employee groups within professional service firms. Human Resource Management, 50 (3), 341-363.

Menguc, B., \& Auh, S. (2008). The asymmetric moderating role of market orientation on the ambidexterity-firm performance relationship for prospectors and defenders. Industrial Marketing Management, 37 (4), 455-470.

Michelson, G., van Iterson, A., \& Waddington, K. (2010). Gossip in organizations: Contexts, consequences and controversies. Group \& Organization Management, 35(4), 371-390. 
Mihalache, O.R., Jansen, J. J. P., Van den Bosch, F. A. J., \& Volberda, H. W. (2014). Top management team shared leadership and organizational ambidexterity: A moderated mediation framework. Strategic Entrepreneurship Journal, Article first published online: 25 OCT 2013.

Mom, T. J., Van den Bosch, F. A. J., \& Volberda, H. W. (2009). Understanding variation in managers' ambidexterity: Investigating direct and interaction effects of formal structural and personal coordination mechanisms, Organization Science, 15 (4), 812-828.

Nadkarni, S., \& Herrmann, P. (2010). CEO personality, strategic flexibility, and the firm performance: The case of the Indian business process outsourcing industry. Academy of Management Journal, 53, (5), 1050-1073.

Nemanich, L., \& Vera, D. (2008). Transformational leadership and ambidexterity in the context of an acquisition. The Leadership Quarterly, 20, 19-33.

O’Leary, M. (2003). From paternalism to cynicism: Narratives of a newspaper company. Human Relations, 56 (6), 685-704.

O’Reilly, C. A., III, \& Tushman, M. L. (2004). Ambidexterity as a dynamic capability: Resolving the innovator's dilemma. Research in Organizational Behavior, 28, 185-206.

O’Reilly, C. A., III, \& Tushman, M. L. (2008). The ambidextrous organization. Harvard Business Review, 82 (4), 74-81.

O’Reilly, C. A., III, \& Tushman, M. L. (2011). Organizational ambidexterity in action: How managers explore and exploit. California Management Review, 53 (4), 5-22.

O’Reilly, C. A., III, \& Tushman, M. L. (2013). Organizational ambidexterity: Past, present, and future. Academy of Management Perspectives, 27(4), 324-338.

O’Reilly, C. A., III, Harreld, J.B., \& Tushman, M. L. (2009). Organizational ambidexterity: IBM and emerging business opportunities. California Management Review, 51 (4), 75-99.

Patel, P., Messersmith, J., \& Lepak, D. (2013). Walking the tightrope: An assessment of the relationship between high performance work systems and organizational ambidexterity, Academy of Management Journal, 56(5), 1420-1442.

Peters, T., \& Waterman, R.H. (2004). In search of excellence: Lessons from America's best-run companies (Second Edition). USA: Profile Books.

Pfeffer, J. (1978). Organizational design. USA: AHM Publishing Company Limited

Polonsky, M.J., \& Waller, D.S. (2005). Designing and managing a research project: A business students guide. London, UK: Sage Publishing. 
Prior, L. (2003). Using documents in social research. London, UK: Sage Publishing.

Prieto, I.M., \& Santana, P.P. (2012). Building ambidexterity: The role of human resource practices in the performance of firms from Spain. Human Resource Management, 51, (2), 189-212.

Quinn, J.B. (2003). Strategic change: Logical incrementalism. In J.B. Quinn \& H. Mintzberg (Eds.), The strategy process (Fourth Edition). USA, Prentice Hall.

Raisch, J., \& Tushmann, M. (2011). A dynamic perspective on ambidexterity: Structural differentiation and boundary activities. Harvard Business School Working Paper, August.

Raisch, S., \& Birkinshaw, J. (2008). Organizational ambidexterity: Antecedents, outcomes, and moderators. Journal of Management, 34 (3), 375-409.

Raisch, S., Birkinshaw, J., Probst, G., \& Tushman, M.L. (2009). Organizational ambidexterity: Balancing exploitation and exploration for sustained performance. Organization Science, 20 (4), 685-695.

Rao, M.G., \& Rao, V.S.P. (1999). Organization design, change and development: Text and Cases. India: Discovery Publishing.

Roan, S. (2009). The key to happiness is living in the micro-moment. Los Angeles Times, accessed 23 May 2011 at latimesblogs.latimes.com/booster_shots/2009/07/happiness.html.

Rothaermel, F. T., \& Alexandre, M. T. (2009). Ambidexterity in technology sourcing: The moderating role of absorptive capacity. Organization Science, 20 (4), 759-780.

Russo, A., \& Vurro, C. (2010). Cross-boundary ambidexterity: Balancing exploration and exploitation in the fuel cell industry. European Management Review, 7 (1), 30-45.

Sarkees, M., Hull, J., \& Prescott, J. (2010). Ambidextrous organizations and firm performance: The role of marketing function implementation. Journal of Strategic Marketing, 18 (2), 165184.

Shafer, R.A., Dyer, L., Kilty, J., Amos, J., \& Ericksen, J. (2001). Crafting a human resource strategy to foster organizational agility: A case study. Human Resource Management, 40 (3), 197-211.

Shaw, P. (2010). Defining moments. Basingstoke, UK: Palgrave-Macmillan.

Shaw, P. (2012). The age of agility. London, UK: Praesta Partners.

Simesk, Z. (2009). Organizational ambidexterity: Towards a multilevel understanding. Journal of Management Studies, 46 (4), 59-624. 
Simsek, Z., Heavey, C., Veiga, J.F., \& Souder, D. (2009). A typology for aligning organizational ambidexterity's conceptualizations, antecedents, and outcomes. Journal of Management Studies, 46 (5), 864-894.

Smith, W.K., \& Tushman, M.L. (2005). Managing strategic contradictions: A top management model for managing innovation streams. Organization Science, 16(5), 522-536.

Stacey, R. (2012). Tools and techniques of leadership and management: Meeting the challenge of complexity. London, UK: Routledge.http://sites.google.com/site/andrespicer/Autonomyjune09submitted.doc?attredir ects $=0$

Spicer, A., Alvesson, M., \& Kärreman, D. (2009). Critical performativity: The unfinished business of critical management studies. Human Relations, 62(4), 537-560.

Stanford, N. (2004). Organization design: The collaborative approach. London, UK: ButterworthHeinemann.

Stokes, P. (2011). Critical concepts in management and organization studies. Basingstoke, UK: Palgrave Macmillan.

Stokes,P., \& Harris,P. (2012). Micro-moments, choice and responsibility in sustainable organizational change and transformation: The Janus dialectic. Journal of Organizational Change Management, 25 (4), 595 - 611.

Taylor, A., \& Helfat, C.E. (2009). Organizational linkages for surviving technological change: Complementary assets, middle management, and ambidexterity, Organization Science, 20 (4), 718-739.

Tiwana, A. (2007). Do bridging ties complement strong ties? An empirical examination of alliance ambidexterity. Strategic Management Journal, 29, 251-272.

Triplett, J.M. (2007). Organizational design: A holistic view. USA: Collective Erudition Publishing.

Turner, N., \& Lee-Kelley, L. (2013). Unpacking the theory on ambidexterity: An illustrative case on the managerial architectures, mechanisms and dynamics. Management Learning, 44(2), 179-196.

Turner, N., Swart, J., \& Maylor, H. (2013). Mechanisms for managing ambidexterity: A review and research agenda. International Journal of Management Reviews, 15(3): 317-332.

Tushman, M.L., \& O’Reilly, C.A. (1996). Ambidextrous organizations: Managing evolutionary and revolutionary change. California Management Review, 38 (4), 8-30. 
Tushman, M. L., Smith, W. K., \& Binns, A. (2011). The ambidextrous CEO. Harvard Business Review, 89(6): 74-80.

Van Maanen, J. (1988). Tales of the field: On writing ethnography. Chicago, USA: University of Chicago Press.

Van Maanen, J. (2010). A song for my support: More tales of the field. Organizational Research Methods, 13 (2), 240-255.

Vince, R., \& Broussine, M. (1996). Paradox, defense and attachment: Accessing and working with emotions and relations underlying organizational change. Organization Studies, 17, 1-21.

Voss, G.B., \& Voss, Z.B. (2013). Strategic ambidexterity in small and medium-sized enterprises: Implementing exploration and exploitation in product and market domains. Organization Science, 24(5), 1459-1477.

Waddington, D. (2004). Participant observation. In C. Cassell, \& G. Symon (2004). Essential guide to qualitative methods in organizational research. London, UK: Sage Publications.

Wang, C. L., \& Rafiq, M., (2014). Ambidextrous organizational culture, contextual ambidexterity and new product innovation: A comparative study of UK and Chinese high-tech firms. British Journal of Management, 25(1), 58-76.

Watson, T., \& Harris, P. (1999). The emergent manager. London, UK: Sage Publications.

Weick, K.E. (1995). Sensemaking in organizations (Foundations for organizational science). London, UK: Sage Publications.

Weick, K.E. (2009). Making sense of the organization, Volume 2: The impermanent organization. London, UK: John Wiley \& Sons.

Weber, Y., Rachman-Moore, D., \& Tarba, S.Y. (2012). HR practices during post-merger conflict and merger performance. International Journal of Cross Cultural Management, 12(1), 7399.

Weber, Y., \& Tarba, S.Y. (2010). Human resource practices and performance of mergers and acquisitions in Israel. Human Resource Management Review, 20, 203-211.

Willmott, H. (2005). Theorizing contemporary control: Some post-structuralist responses to some critical realist questions. Organization, 12(5), 747-780.

Winter, S.G., \& Szulanski, G. (2001). Replication as strategy. Organization Science, 12 (6), 730743. 
Wisser, M. (2010). Critical management studies and 'mainstream' organization science: A proposal for a rapprochement. International Journal of Organizational Analysis, 18(4), 466 $-478$.

Yang, T.T., \& Li, C-R. (2011). Competence exploration and exploitation in new product development. Management Decision, 49(9), 1444-1470.

Yin, R.K. (2009). Case study research: Design and methods (Fourth Edition). London, UK: Sage Publishing.

Table I

\section{Foregrounding Conditions of:}

\section{Organizational Ambidexterity in the Intra-Firm Context}

Embracing the operation of general principles of:

Simultaneous juxtaposition and complementarity of modernism and critical perspectives: 


\begin{tabular}{|c|c|}
\hline \multicolumn{2}{|c|}{ Grounded on... Parallel yet competing sense-making paradigms } \\
\hline \multicolumn{2}{|c|}{ Producing and resulting in ... Differing communities of sense-making/perspectives. } \\
\hline .... Portrayed and & llustrated through: \\
\hline \multicolumn{2}{|c|}{$\begin{array}{l}\text { (Focal Conditions at the Boundary of exploitative and exploratory } \\
\text { OA:) }\end{array}$} \\
\hline EXPLOITATIVE STATES \& CONDITIONS & EXPLORATORY STATES \& CONDITIONS \\
\hline $\begin{array}{l}\text { Normative (i.e. displayed in behaviors pertaining to } \\
\text { linear, reductionistic, causal in nature and appearance). } \\
\text {-'As long as we adhere to the standard procedures and } \\
\text { operating procedures all should be fine'. } \\
\text { [Example: A strong tendency by some employees to } \\
\text { stick to long-standing organizational fixed procedures; } \\
\text { constantly look at the cost as opposed to the value- } \\
\text { added of the proposition; Little emphasis placed on } \\
\text { culture development; a belief in stability - all is well, } \\
\text { everyone is happy and works very hard.' Employee 72]. }\end{array}$ & $\begin{array}{l}\text { Critically orientated (i.e. displayed in behaviors } \\
\text { pertaining to non-linear, embracing rich pictures and } \\
\text { see multiple causes in operation). } \\
\text { [Example Observation: the spontaneous setting up of } \\
\text { self-organizing action groups]. }\end{array}$ \\
\hline $\begin{array}{l}\text { Exhibiting positivistic/post-positivistic (i.e. these are } \\
\text { akin to normative postures and show a sense-making } \\
\text { pattern that is non-expansive and prone to the } \\
\text { exploitative). }\end{array}$ & $\begin{array}{l}\text { Exhibiting critical perspective tendencies and show a } \\
\text { sense-making pattern that is expansive and prone to the } \\
\text { explorative). } \\
\text { [Example: 'It is good to loosen things up a lot - create } \\
\text { a bit of 'organized chaos' - sometimes it is nice to not } \\
\text { to know what might happen tomorrow or in the next } \\
\text { period - what might come through!' Employee 18]. }\end{array}$ \\
\hline Tending to exhibit characteristics of: & Tending to exhibit characteristics of: \\
\hline
\end{tabular}




\begin{tabular}{|c|c|}
\hline $\begin{array}{l}\text {-A generally believed to be espoused rationality- } \\
\text { 'common sense', } \\
\text { - linear in nature } \\
\text { - causal in nature - simple cause and effect } \\
\text {-Reductionism - artificially attempting to simplify } \\
\text { problems in order to identify 'answers' }\end{array}$ & $\begin{array}{l}\text { - competing rationalities, } \\
\text { - rhizomatic in nature, } \\
\text { - myriad cause and effects in simultaneous action and } \\
\text { process } \\
\text { - a willingness to see issues and problems holistically - } \\
\text { multiple solutions possible. } \\
\text { ['Everything is happening and there is a really good } \\
\text { vibe. Some days it feels chaotic but it feels good.' } \\
\text { Employee 39]. }\end{array}$ \\
\hline $\begin{array}{l}\text { Consolidating/controlling (i.e. prone to adhering to the } \\
\text { reductionistic and linear tendencies). }\end{array}$ & $\begin{array}{l}\text { Emancipatory / empowering (i.e. prone to adhering to } \\
\text { the expansive and emancipatory postures). }\end{array}$ \\
\hline Tendency to espouse and seek stability and order. & $\begin{array}{l}\text { Tendency to recognize and embrace the prevalence of } \\
\text { periodic chaotic patterns and trends. }\end{array}$ \\
\hline $\begin{array}{l}\text { ['That is the way we have always done things round } \\
\text { here. Why change? It works doesn't it?' Employee 24]. }\end{array}$ & $\begin{array}{l}\text { Essentially externally focused and externally focused } \\
\text { mind-set. } \\
\text { ['It is really important to get out of the office from time } \\
\text { to time and meet external organizations and clients in } \\
\text { order to discover and develop new ideas'. Employee } \\
40 \text { ]. }\end{array}$ \\
\hline $\begin{array}{l}\text { Tendency to allow limited empowerment. } \\
\text { ['Please run it through your line manager and then it } \\
\text { will have to go through committee X.' } \\
\text { Employee 71]. }\end{array}$ & $\begin{array}{l}\text { Tendency to afford extensive emancipation and liberal } \\
\text { free-ranging autonomous action through micro- } \\
\text { moments and choice. } \\
\text { ['Yes, that is a great idea - run with it and please let us } \\
\text { know what support or resource you need.' } \\
\text { Employee 54]. }\end{array}$ \\
\hline $\begin{array}{l}\text { Prone to adopting constraining mode of the change } \\
\text { initiative described in the case. }\end{array}$ & $\begin{array}{l}\text { More disposed to expansive mode of the change } \\
\text { initiative described in the case. }\end{array}$ \\
\hline $\begin{array}{l}\text { Tendency for meta-narratives to predominate - these } \\
\text { tend to tell stories of the firm (and even the firm and its } \\
\text { industry as a whole) as if there were some form of } \\
\text { common agreement about the context in which it } \\
\text { operates. }\end{array}$ & $\begin{array}{l}\text { Tendency for multiple narratives to predominate m- } \\
\text { tendency to see and identify myriad and multifarious } \\
\text { stories simultaneously occurring through on-going } \\
\text { multiple exchanges and sense-making. }\end{array}$ \\
\hline
\end{tabular}




\begin{tabular}{|l|l|}
\hline $\begin{array}{l}\text { [That has never been the Company ' } x \text { ' way'. Employee } \\
\text { 67]. }\end{array}$ & $\begin{array}{l}\text { ['We live in a complex sector and a difficult world and } \\
\text { we have to accept that and get on with it.' Employee } \\
10] .\end{array}$ \\
\hline Tends to lean to data analysis and managing. & Tends to lean towards leadership, shaping and intuition. \\
\hline
\end{tabular}

\section{Diagram 1:}

Representation of the interaction and surrounding contexts of the dependent and independent variables.

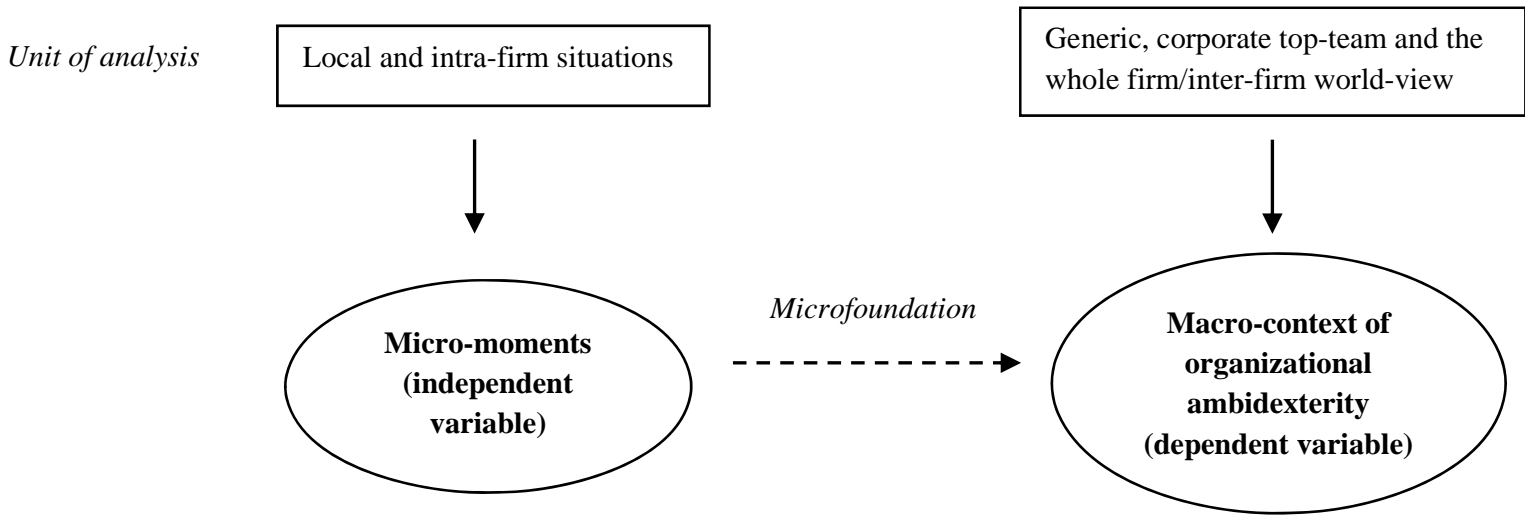



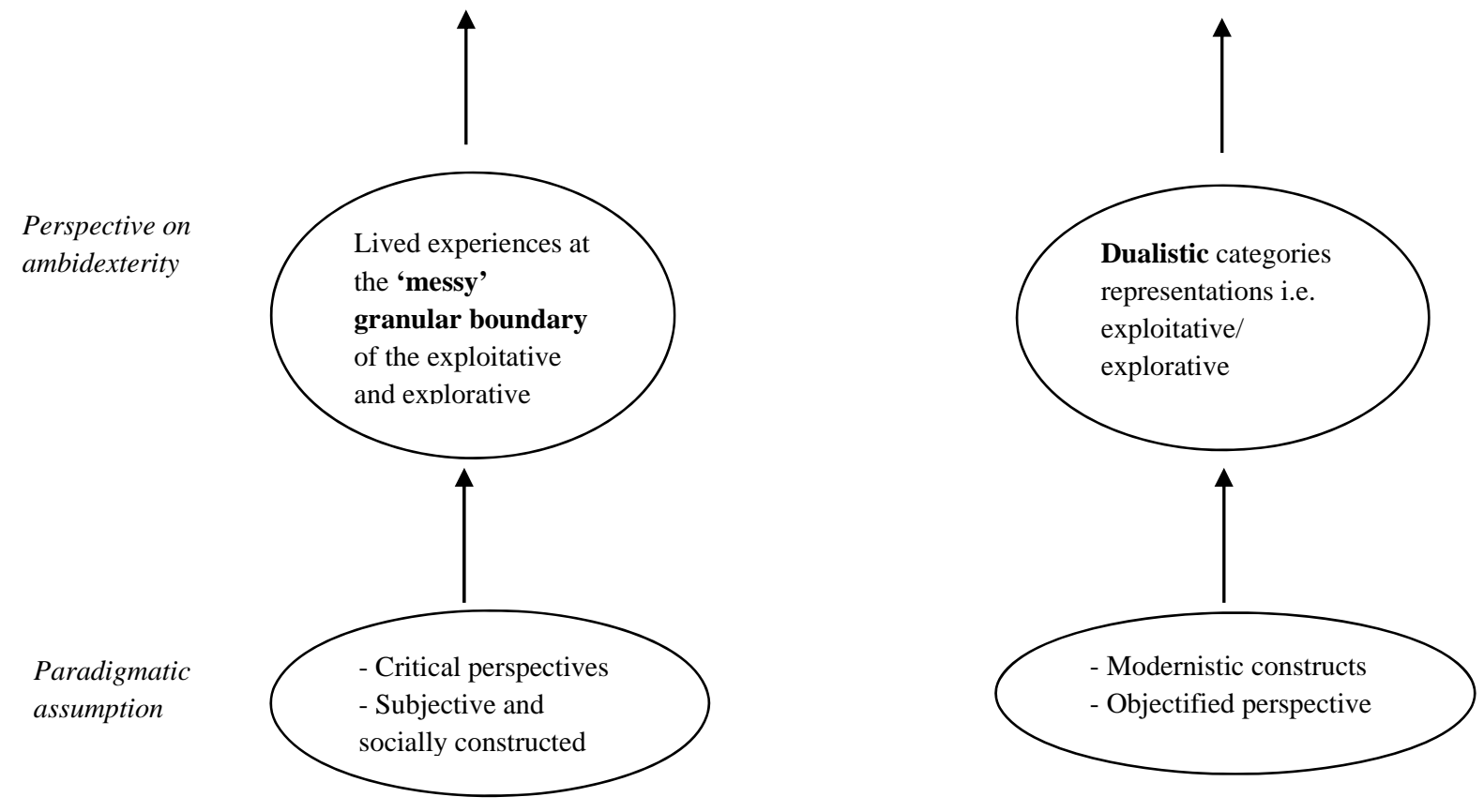